\title{
Strings Across the Ocean: Practices, Traditions, and Histories of the Cocos Malay Biola in the Cocos (Keeling) Islands, Indian Ocean
}

David R. M. Irving

ICREA \& Institució Milà i Fontanals de Recerca en Humanitats-CSIC, Barcelona, Spain

\begin{abstract}
The biola (violin) is an emblematic musical instrument of the Cocos Malay community, who have been based on the Cocos (Keeling) Islands-part of Australia's Indian Ocean Territories-since 1826. In Cocos Malay culture, the biola accompanies local dance genres and occasional performances of bangsawan theatre. Malay melodies constitute the bulkof the repertoire; there are also melodies exhibiting Scottish characteristics. The latter are often attributed to the influence of the Clunies-Ross family, who maintained a commanding presence on the islands from 1827 to 1978. Since the mid-twentieth century, biola playing has been the preserve of two families on the islands and in Western Australia. The practice has declined over the past two decades, owing to a decrease in players; however, a revitalisation programme was initiated in 2014. This article explores aspects of the practice and cultural functions of the biola on Cocos and documents the history of the instrument on the islands, drawing on data from ethnographic and archival research.
\end{abstract}

\section{KEYWORDS}

biola (violin); Cocos (Keeling) Islands; Cocos Malay music; revitalisation

\section{Introduction}

The biola (violin) has played a major role in Malay and Malayic cultures across the Malay-Indonesian archipelago since at least the late sixteenth century. It was absorbed definitively into many Malay communities, and developed a longstanding tradition of practice in the Malay-speaking world, where it has become indigenised (see, for instance, Scarfe and Hasbi 2019). While the process of its indigenisation can be compared with other well-known cases of cross-cultural transfer-such as the absorption and prominence of the violin within Karnatak classical music from the late eighteenth century (Weidman 2006: 25-58; Swift 1990) or the guitar in Polynesian music cultures (Fellezs 2019) - the local appropriation of the violin appears to have 
taken place at an earlier date in the Malay world. Historical evidence of its earliest introduction remains hazy, but the instrument is often assumed to have arrived in Southeast Asia via the Portuguese trade routes in the late sixteenth century (for example, Matusky and Tan 2004: 322). The Malay word biola, the use of which dates back several centuries, is acknowledged as being of Portuguese origin (Gullick 1987: 342). ${ }^{1}$ Margaret Kartomi has outlined the exodus of slave musicians from the Portuguese colony of Melaka following the capture of the city by Dutch forces in 1641 (2012: 10-11), and hypothesises that biola players fleeing from this conflict may have entered the service of Malay courts in Sumatra. The influence of these musicians, and others, likely spread further afield. An easily transportable instrument, the biola regularly accompanied travellers on ships and boats; it was known in many islands, used by local inhabitants, visiting traders, and colonialists alike. As far east as the Sulu Archipelago and Mindanao, the biola was noted to be used in indigenous musical contexts in the mid-eighteenth century; however, its introduction to these regions (where it became known as biyula) was probably also due to influence emanating from Manila (Irving 2010: 64-65), colonised by Spain via Mexico, across the Pacific.

By the late eighteenth century the biola was a fixture in the Malay world. In 1783 British scholar and linguist William Marsden wrote of the instrument's use in communities on the west coast of North Sumatra, emphasising its route of transmission across the Indian Ocean: 'The violin has found it's [sic] way to them from the westward' (1783: 159). Interestingly, the way Marsden phrases this statement of origins assigns agency to the instrument itself, implying an absorption of the biola into local music cultures that was independent from contexts of direct cultural imposition. Malay players were respected in British colonies: for instance, in early nineteenth-century Penang, a Malay musician named Che Draman was known to the British as 'their Neil Gow', the epithet probably indicating that he played the same instrument as the famous Scottish fiddler of that name (Irving 2014: 207-209). Dutch colonialists also owned slaves who played on the violin and other instruments; a whole orchestra of slave musicians was auctioned in Jakarta in 1833 (Gibson-Hill 1952: 168-169). Throughout the Malay world, during the period of British and Dutch colonial rule and after

\footnotetext{
${ }^{1}$ However, the closest cognate term in Portuguese-viola-referred generically to a broad range of string instruments from the mid-fifteenth to late eighteenth centuries. These included the viola da gambaand, most frequently, the guitar (see Budasz 2001: 11).
} 
independence, the biola has been used for dance and theatre genres such as bangsawan, zapin, ronggeng, ghazal, komedie stamboel, and orkes melayu (Matusky and Tan 2004: 65, 128-129, 320-322, 344, 352; Weintraub 2010; Cohen 2006). The biola was thus fully embraced within Malay music; nevertheless, it remains an instrument that also has a global reach and is shared with other cultures.

A sphere of biola practice that is connected to-but arguably distinct frommainstream practices in the Malay world is found among the Cocos Malay community on the Cocos (Keeling) Islands. ${ }^{2} \mathrm{~A}$ coral atoll of 27 islands with a total geographical area of $14 \mathrm{~km}^{2}$, the Cocos (Keeling) Islands (hereafter Cocos) are located approximately halfway between Perth and Sri Lanka (map 1); with Christmas Island they constitute Australia's Indian Ocean Territories. Only two islands on Cocos are inhabited today: Home Island and West Island (see map 2). A ferry across the lagoon takes aroundhalf an hour, and one can stroll around the perimeter of Home Island in under an hour. Today around 400 Cocos Malays live in the kampong (Malay community) on Home Island, while approximately 150 other residents are based on West Island, where the airport, a number of businesses, and government facilities are located. The Cocos Malays are the oldest established Muslim community within the Commonwealth of Australia; their customs are protected by law, under section 18 of the Cocos (Keeling) Islands Act of 1955 (Australian Government 2018). ${ }^{3}$ They are descended from the original inhabitants of the islands who arrived there in 1826, and because of the history of this first settlement there have even been occasional proposals for Cocos Malays to be recognised as an indigenous community within Australian society (see Herriman, Irving, et al. 2018).

On Home Island, the biola has been used in a variety of cultural contexts, in diverse and subtly inflected ways. It is not usually played as a performance of solo instrumental music (unless demonstrations are being made), but is used in the context of dance, song, or music-drama. Principally, the presence of a biola player symbolisesvisually and aurally-entertainment or celebration in annual festivities or on the

\footnotetext{
${ }^{2}$ The parenthetical qualification 'Keeling' is used to distinguish these islands from other islands called 'Cocos' in the Pacific and Indian Oceans, and in the Caribbean.

${ }^{3}$ The relevant clause, dating from 1955, states: 'The institutions, customs and usages of the Malay residents of the Territory shall, subject to any law in force in the Territory from time to time, be permitted to continue in existence' (Australian Government 2018, section 18).
} 
occasion of life cycle events, especially weddings. It is sometimes also incorporated into the framing of performances that mark official visits by VIPs, or historical commemorations. The prestige of any such celebration is automatically enhanced by the participation of biola players; there is a demarcated performance space, where the players are seated, and visual attention is drawn to the instrumentalists as well as the dancers.

A perceived peculiarity of the Cocos Malay biola tradition, often commented on by external observers, is the 'Scottish' character of some of its melodies, and the use of the biola to accompany dance types that resemble Scottish traditional performance genres. This Scottish influence is usually attributed to the autocratic rule of the CluniesRoss family, with close connections to Scotland and England, who for five generationsfrom 1827 to 1978 - controlled the islands and their community. As Pauline Bunce observes,

elements of English-Scottish traditions have ... been absorbed into Cocos Malaycultural practices. Certain foods, dances and musical influences have a decidedly western flavour. This is especially obvious during the New Year's Eve celebrations (31 December). On this occasion Scottish reels are danced with great enthusiasm by Cocos Malay people wearing traditional island attire-to the accompaniment of Malaydrums and violins. (1988: 66-67)

While the practice of performing Scottish dances for the Gregorian New Year disappeared from the islands in the 1990s, these genres still emerge on other occasions today, such as the celebrations following Hari Raya (Eid al-Fitr), the end of the fasting month of Ramadan. The mix of Scottish (and English) traditions with Malay practices in the relatively short history of permanent human settlement on the islands - still less than two hundred years old-is a narrative of musical genealogy that is regularly borne out in conversations with the islanders themselves, from an emic perspective. It is also a longstanding trope from an etic viewpoint: colonial archival records and reports of travellers that include observations of this hybrid phenomenon can be traced back to at 
least the late nineteenth century, although these sources are of course one-sided and inherently biased. ${ }^{4}$

In some academic and political discourse about the islands, the biola symbolises the hybrid nature of Cocos Malay culture and evokes the cultural impact of the CluniesRoss regime (e.g. Tahmindjis 1985: 198). Yet the presence of the biola on the islands and its integration within Cocos Malay culture must be considered in the broader context of two different colonial encounters: first, the introduction of the instrument to Southeast Asia in the sixteenth and seventeenth centuries, conventionally attributed to the Portuguese and the Dutch; and second, the layering of Scottish (and generic British) practices from the late eighteenth or early nineteenth centuries, which coalesced and blended with the existing Malay use of the instrument. ${ }^{5}$ Given that the biola came to Cocos with the first settlers of the islands in the 1820s, it is thus important to consider the biola today as an asli (original) Cocos Malay instrument, fully absorbed and indigenised within traditional cultural frameworks. As Jason Toynbee and Byron Dueck put it, 'certain practices, instruments, and sounds-some appropriated in the heightened mimetic context of colonial or imperial encounter-[can] become thoroughly indigenized in their new contexts' (2011: 8). This is arguably the case for the Cocos Malay biola, which has become a symbol for the continuity of traditional Cocos Malay culture in the face of rapid change and the impact of modernisation.

Although the Cocos Malay community was geographically and socially isolated and had limited contact with the outside world during the period of Clunies-Ross rule, realignment with the mainstream Islamic world and integration with Australian society have taken place over successive generations since the 1970s. These influences have wrought numerous changes in the culture of the islands. Although islands have long been a popular locus of anthropological and ethnomusicological research, the notion of

\footnotetext{
${ }^{4}$ Meanwhile, the earliest written account of Malay music and dance on the islands, without indications of European influence, was made by none other than Charles Darwin, during his Beagle voyage (1839: 546). See Irving forthcoming.

${ }^{5}$ While its name is indicative of its foreign origins, the same can be observed of other instruments, such as the Malay serunai (shawm) whose name and form is similar to the surnay of Iran and zurna of Turkey (Matusky and Tan 2004: 24). The assumed 'Europeanness' of the violin arguably does not minimise its importance in Malay and South Asian music cultures (besides others) for almost five centuries. Paradoxically, European organologists have tended since the nineteenth century to emphasise that bowed instruments have their origins in Asia (e.g. Fétis 1856; Bachmann 1969; Montagu 2007: 161).
} 
islands as 'bounded' communities has been reappraised, with recent studies demonstrating a great deal of change and movement (see examples in Dawe 2004). Migration from Cocos to the Australian mainland over the past half-century has been rapid, as has marriage migration from the Cocos Malay community in Sabah (Winarnita and Herriman 2012). The Cocos Malay diaspora is remarkably widespread today, with communities in many parts of Western Australia-in Perth, Katanning, Bunbury, Geraldton, and Port Hedland-as well as in eastern Australia (Sydney and Yass), the Malaysian state of Sabah (Tawau, Lahad Datu, and other regions), and elsewhere. The biola has travelled with musicians to many of these places.

Despite almost half a century of integration of Cocos Malays within Australian society, their culture and history are not widely known. Unlike other islands a few hours' flight away from the Australian continent (especially in the Pacific), there was essentially no tourism on the islands until the 1990s; today a commercial passenger aeroplane arrives on Cocos just twice a week. The lack of general commercial travel to the islands and the considerable expense involved in getting there has also meant that, until quite recently, the majority of studies on Cocos from the fields of the sciences, social sciences, and humanities were undertaken by scholars present there for other kinds of work, such as government administration, or the provision of health services or education. ${ }^{6}$ With the increasing accessibility of the islands to visitors, however,Cocos Malay culture, history, and the Cocos Malay language (recognised by linguists as a Malay-based Creole; see Soderberg 2014) are now becoming burgeoning areas of academic research. Music is the most recent discipline to join the field. ${ }^{7}$

In this small and remote community, Islamic religious sound provides a daily structure for life and work, but most public performances of music and dance take place

\footnotetext{
${ }^{6}$ Some of the most prominent scholarship is by Pauline Bunce (1988; 2012), John Hunt (1989), and Alastair Welsh (2015), who were present on the islands respectively as a schoolteacher, a public servant, and a government interpreter.

${ }^{7}$ Although the Cocos (Keeling) Islands were not the subject of research in ethnomusicology and music history until recently, music and dance had been present as part of the cultural backdrop for studiesby historians, linguists, and anthropologists. Current research projects on topics related to Cocos Malay culture and history are being carried out by anthropologists Monika Winarnita and Nicholas Herriman, ethnomusicologist Jenny McCallum, linguists Alastair Welsh and Craig D. Soderberg, historian Michael Laffan, and me. There are also studies of music and dance within the Cocos Malay community of Sabah, Malaysia, currently under way; see, for instance, Kamaruddin and Aziz 2018.
} 
in concentrated periods for the religious festivals of Hari Raya (Eid al-Fitr, marking the end of Ramadan) and Maulud Nabi (the Birthday of the Prophet), as well as for weddings. On these occasions relatives and friends visit Home Island from Australiaand the Malay world, and the kampung's tiny population swells considerably. In 2015 and 2016, thanks to a Discovery Project grant from the Australian Research Council, administered through the Melbourne Conservatorium of Music, the University of Melbourne, I was privileged to be able to carry out with Jenny McCallum several periods of fieldwork on $\operatorname{Cocos}^{8}$ Our research budget did not permit us to undertake fieldwork for a sustained six- or twelve-month period, due to the considerable costs of travelling to and staying in the islands. However, given that musical activity is concentrated in a few specific weeks of the year, three separate field trips (which spanned from the preparations for the festivals to their conclusion) permitted us to observe a wide range of cultural practices. We were present for two celebrations of Hari Raya on Cocos, and one of Maulud Nabi celebrated by the Cocos Malay community of Katanning, Western Australia. A total of ten weeks of intensive on-site research enabled us to observe, among other things, the current state of biola playing on Cocos and in Katanning, and to consider cultural and social dimensions such as the cultural prestige accorded to the instrument and the social exclusivity surrounding its practice. ${ }^{9}$ Our understanding of the history of unique contexts of transplanted cultures and hybridised practices on Cocos was rounded out by forays into archives in Canberra and the United Kingdom. In what follows, I explore the history and cultural significance of biola playing in the Cocos Malay community, contextualising it within the broader framework of the practice of other instruments on Cocos, describing some of the established techniques and genres that are currently in use, and reflecting on the implications of recent changes in the artforms. On the basis of islanders' own narratives and through the consideration of data drawn from colonial archives, I speculate on the origins of the biola's presence on the islands: evidence suggests that the instrument was present

\footnotetext{
${ }^{8}$ Jenny McCallum, an ethnomusicologist specialising in musics of the Malay world, worked as a Research Associate 2015-2017 on this Australian Research Council Discovery Project. She speaks Malay fluently and adapted quickly to Cocos Malay usage; I depended on her expertise in translating the stories we heard, and am grateful for her insights into many of the finer points of Cocos Malay culture.

${ }^{9}$ A planned period of fieldwork among the Cocos Malay community in Sabah, Borneo, had to be cancelled for reasons of logistics and health; instead, we undertook an additional research trip to Cocos.
} 
there from the time of first settlement in 1826. Finally, in a discussion of historical accounts of biola performance on Cocos, I demonstrate the interest that the instrument and its practice have long held for etic observers. All these factors point to the biola being an inseparable part of traditional Cocos Malay culture (kebudayaan), absorbed and indigenised as a local musical practice and part of the islanders' identity.

\section{The Position of the Biola in Instrumental Practice on Home Island}

Many instruments have been practised by the Cocos Malay community on Home Island, as can be ascertained from interviews and archival sources. These have been introduced at different points in the islands' history, and not all are in use today. They include various kinds of Malay drums (rebana, kompang, ${ }^{10}$ gendang, and beduk); certain gamelan instruments, which were used to accompany wayang (the Javanese puppet theatre, introduced to the islands in the 1860s; see Hunt 1989: 46) but discarded after the death of the last wayang puppeteer; various aerophones such as the harmonica, accordion, and even the recorder; and string instruments such as guitar and biola. During the Second World War, there briefly arrived the most emblematic of Scottish instruments-highland bagpipes-played in 1945 by a Punjabi regiment stationed on West Island. ${ }^{11}$ In the second half of the twentieth century, Cocos Malaymusicians embraced instruments for popular music such as the drum kit, electric guitars, synthesisers, and bongos. The electric violin was introduced in 2015.

Within the traditional Cocos Malay instrumentarium, it is possible to distinguish three distinct groups: 1 . instruments that possess cultural prestige as symbols of the community's tradition and kebudayaan (culture); 2 . those that are now fully embraced and naturalised; and 3. those that have fallen out of use (harmonica, accordion, recorder, and some gamelan instruments), and do not appear to have been replaced. Although some women and girls play rebana in private contexts, instrumental music

\footnotetext{
${ }^{10}$ The terms rebana/kompang are sometimes used interchangeably, but strictly speaking the rebana is larger and has jingles. It is analogous to the tar drum used in Malaysia (Matusky and Tan 2004:261). ${ }^{11}$ The only archival evidence of bagpipes on Cocos is from 1945: on 10 May, 400 Cocos Malays travelled to West Island for celebrations of the Allied victory in Europe, and they heard a Punjabi regimentplay these instruments on West Island. According to a report located in British military records, the Cocos Malay observers were 'particularly impressed'. (J. A. Harvey, 'Report for the month of May 1945', 1, in 'Cocos Islands: Emergency Organisation', National Archives of the United Kingdom, CO273/673/9).
} 
appears to be predominantly a male activity. As Veronica Doubleday points out in a global sense, 'the realm of musical instruments is characterised by gender inequalities, with men dominating instrumental musicianship and technology' (2008: 29). However, one grandmother remarked that she had always wanted to learn biola as a child, and maybe now-with the initiation of the Shire Council's revitalisation project-she could, as an adult. ${ }^{12}$ The instruments that are most valued in traditional Cocos Malay musical practices, in terms of cultural prestige, are arguably the rebana/kompang, gendang, and biola. The large drum called beduk could be added to this list; however, it has the role of a stationary ritual object that announces the end of fasting during Ramadan as well as being played through the night at malam takbir, the night that concludes the final day of fasting (Bunce 1988: 81-82). The other drums have a strong association with religious practice, being used in zikir and nasyid, but they are also played for dances (dansa, selong, and melenggok) and occasional performances of bangsawan theatre (see Irving and McCallum forthcoming). The biola, on the other hand, is used for secular music only: instrumental music, to accompany dances, and to accompany bangsawan. Performances of bangsawan are quite rare but one such performance in 2016 was accompanied by electric violin and gendang (see figure 1).

In the accompaniment of dances, there is a clear system of instruments: dansa is accompanied by biola alone; melenggok by biola, rebana, and gendang; and selong by biola and gendang. Silat-a dance evoking martial arts, which wards away malevolent spirits - can also be accompanied by biola. Rabuhu bin Anthony (Haji Adam), now the chief imam of Cocos, writes:

Only male musicians supply music for these dances. For the melengok and the seylong there are nine members in the band, playing four violins, four drums and a tambourine [sic; rebana]. The dangsa is accompanied only by violins. There are nine songs that can be played for the melengok, but many more for the seylong and the dangsa. ${ }^{13}$ (Rabuhu Anthony 2003: 150)

\footnotetext{
${ }^{12}$ Anonymous, personal communication. However, we do not know whether this informant has taken up the biola.

${ }^{13}$ Cocos Malay is predominantly an oral language, and orthography is still being standardised in its written form. The genres mentioned in this quotation are often expressed as melenggok, selong, and dansa.
} 
While some dances it accompanies traditionally had sacred dimensions, such as silat, the biola is unique within Cocos musical culture, as the only instrument of cultural prestige that now plays a purely secular role. Since the 1970s, and arguably earlier (see Hobson 2008 and Hunt 1989), the Cocos Malay community has reintegrated with the mainstream Islamic world, and the secular nature of the biola could be a factor that contributes to its decline in popularity (see similar discussions of dance in McCallum forthcoming-b).

In living memory, the specialist use of the biola has been the monopoly of two families on Cocos and in Western Australia, although other biola players migrated to Sabah, Malaysia, in 1948-1952. When we first visited Cocos in 2015 there were just three biola players on Home Island - two brothers and their nephew: the late Nek Bail (Alpan bin Puria, d. 2016), who kindly demonstrated biola for us but no longer played regularly due to arthritis; his brother Nek Mazlan (Colin bin Puria), who played several pieces for me when we first met, but who has retired from playing; and their nephew Nek Yusri (Zainal bin Wallie), who is currently the leading player on Cocos. ${ }^{14}$ In Katanning and Geraldton, Western Australia, there are other players from another biola-playing family; we met one such individual in Katanning (Haji Krup, also Nek Salanie or Krup bin Iman), who said that he and his brother played biola. The highly prized technical and aesthetic skills of these musicians have been passed down through multiple generations. Members of the Cocos Malay community have traditionally known the identity and location of these players, and seek them out especially for weddings, events that solidify the biola's function in accompanying celebratory rituals of social cohesion and enhance the prestige of instrument and player alike. Biola players on Home Island and in the diaspora (Sabah and Western Australia) are aware of each other; as we note below, Pak Melati, a biola player from Sabah (Malaysian Borneo), gifted to Nek Yusri a compact disc recording of his repertoire. Nek Yusri (shown in figure 1) is currently the only specialised practitioner of biola trained in the traditional method of intra-family knowledge transmission; recently, however, he has taken on

\footnotetext{
${ }^{14}$ Members of the Cocos Malay community have two names: their birth name ([givenname], son/daughter of [father's name]), and the name that they take at the birth of their first child (teknonym). The teknonym changes again at the birth of their first grandchild. The prefix 'Pak' (for father) and 'Mak' for mother is used for parents, and 'Nek' (for both genders) used for grandparent. See Herriman 2014.
} 
some adult students as a result of the local Shire Council's revitalisation project. During fieldwork in 2015 and 2016, Nek Bail, Nek Mazlan, and Nek Yusri kindly described and demonstrated to us their skills and knowledge.

\section{Cocos Malay Biola Practice, Theory, and Technique}

In shape and form, the Cocos Malay biola is the same as a conventional European violin. However, the instrument and its bow are held and played differently from a European violin. Like players of historical violins (including myself) and traditional fiddles, Cocos biola players conventionally hold the instrument with the tailpiece to the left of the chin (as in figure 1; see also figure 9), although the chin can sometimes hover over the middle of the tailpiece and some beginners place their chins on the chinrest (see figure 5 below). The bow is tightened so that the stick is straight (rather than concave) and is held with the little finger wedged between the hair, and the thumb and middle fingers held upright (see figure 2). The right elbow hangs low and provides sufficient weight to allow gravity to increase contact and friction between the bow and the string. The interval between each pair of strings appears to be slightly wider than a perfect fifth. There are challenges in tuning in this climate, since the pegs—called kuping (ears)—do not always move smoothly in the humid tropical air. When they are turned, the friction of the wood sometimes makes a cracking sound, indicating that they jolt from point to point within the revolution of the peg shaft, rather than gliding through all possible points. There is thus some variability in the tuning of the open strings each time the instrument is tuned, but for practical purposes their pitches nevertheless lie within a consistent range (clearly set from memory). The lowest (fourth) string was not often observed to be used; interestingly, though, the lowest pair of strings was tuned to an octave for bangsawan repertoire. When playing a melody on the second string, the first string is double-stopped with it; similarly, when the melodic centre moves to the third string, it is double-stopped with the second string. The first (highest) string is the only one to be played alone, since it has no upper neighbour. When accompanying singing, as in bangsawan, the biola elaborates on vocal melodies by adding a parallel upper line; this became apparent when we heard voices joining the biola, singing lyrics known to an assembled group of people. The voices joined with the lower line and the melodic centre was clear to all participants. 
Transcriptions of two dance pieces played by Nek Yusri (Musical examples 1 and 2) broadly demonstrate the branches of the tradition that are typically identified by outside observers as 'Scottish' and 'Malay'. ${ }^{15}$ Musical example 1, a dansa tunetitled 'Burung hitam nyambar di telok' (Black bird lands on the lake), is played mostly in parallel fifths, with the main melody in the lower voice. The texture is almost always in two voices, apart from bars 9, 11, 13, and 15 in Section B, where only the top string is played, since there is no string above it to be played in a pair. The main melody sounds remarkably like a Scottish jig, and this kind of music would account for the historical comparisons (discussed below) with 'old highland tunes' and 'easily recognisable Scottish Airs'. This dansa tune is in a meter that corresponds to compound quadruple time, commonly found in Scottish dance music. The repetition of different sections allows for the full sequence of dance movements, and can be adapted to the number of people participating, or the length of the performance. Ornamentation is added to some notes on repeats; the mordent in bar 6 , however, is left out on the first two repeats and added on the three that follow. The structure of this dansa depends on the number of repetitions needed; after the required number of repeats, a brief coda can be added.

Musical example 2 represents one of the melenggok melodies, for a scarf dance traditionally performed at Cocos Malay wedding celebrations (but now also in other contexts). The rapid oscillation between neighbour notes is a typical expressive device here, and reminiscent of Malay vocalisation in other parts of the Malay world. The slurs in the transcription refer to bowstrokes, and there were pauses and lingering moments

\footnotetext{
${ }^{15}$ These performances were videorecorded by David Irving and Jenny McCallum on 13 July 2016. Videos are available at $<$ LINK $>$ (musical example 1 ) and $<$ LINK $>$ (musical example 2). I have chosen to use staff notation to transcribe these examples, with full acknowledgment and awareness of its representational limitations; the rhythmic notation in the second example, for instance, is inadequate to indicate the passage of pitches in the melody and can only hint at the relationship between tones of longer and shorter duration. I must also stress that the staff is by no means intended to indicate any kind of equal temperament, but simply a broad demonstration of relationship between scale degrees. (The tuning of the note transcribed as a D, for example, was between a conventional D flat and D natural.) The arbitrary modern pitch standard of a' $=440 \mathrm{~Hz}$ (which, it must be remembered, became an international 'standard' only in 1953, when it was ratified by the ISO) is used as an approximate reference point, to indicate that the Cocos biola was-in this performance — tuned almost a fifth below the standardised pitch of a conventional violin in the 'modern' 'Western art music' tradition. When both these pieces were recorded a second time a few weeks later, the tuning was around a tone lower, demonstrating the mutable nature of pitch centres.
} 
at the end of many bowstrokes, although I have not attempted in any way to indicate these prescriptively. On a number of occasions we heard people singing in unison with the lower-pitched note. As was the case in the dansa tune, it is played in parallel fifths (tuned slightly wider than a perfect fifth) with the upper voice dropping out when the melody reaches the top string. The timbre of the biola is strident, cutting through ambient noise; the low position of the instrument and the weight of the bow armallow for considerable pressure on the strings, and with the speed and energy of the bowstroke results in considerable volume. We noted from our conversations with players, and old VHS video recordings made in the 1980s, that loudness of volume is a key characteristic of biola playing, and a highly desirable aesthetic quality, since the instruments had to be audible above the level of group merriment and dancing; presumably for this reason of projection, up to four instrumentalists would play at once. $^{16}$

On 29 July 2016, Nek Yusri played all the repertoire he could think of in a day of recording by Jenny McCallum (see titles in Table 1). He appears to have been inspired to do this following his receipt as a gift of a similar home recording from a biola-playing counterpart, Pak Melati, in a Cocos Malay community in Sabah, Borneo: a compact disc containing fifteen tracks, all but three of which are accompanied by a gendang. ${ }^{17}$ The catalyst seemed to be our questions about the CD that he showed us-inscribed with felt pen 'untuk Nek Yus dari Nek Melati' (for Nek Yus[ri] from Nek Melati)-and the presence of researchers on the islands with appropriate recording equipment, and the prompting of one of his adult children. Nek Yusri intended his recording to be a personal aide-mémoire, and kindly allowed us to keep a copy for research purposes.

\section{Decline and Revitalisation in Biola Culture}

The biola is regularly presented to outsiders as one of the emblems of Cocos Malay music and dance, and part of a living tradition that depends on intergenerational transmission. According to Ray Denholm, the principal of the primary school on Home Island (interview 3 August 2015), one of the school's teachers established a weekly

\footnotetext{
${ }^{16}$ Thanks to Jenny McCallum for this observation.

${ }^{17}$ This recording highlights the need for further research to be undertaken to examine biola practice among the Cocos Malay communities in Sabah.
} 
cultural tour for tourists from West Island during the period 2005-2006. ${ }^{18}$ The children would show visitors sites of interest on Home Island, and the tour finished at the school itself, where there were then demonstrations of cultural activities. These included traditional dance, performances on angklung (instruments used in the school classroom, but then relatively new on Cocos), and the teaching of the biola to schoolchildren by Nek Bail. The children were given a prepared script to read to tourists, which included this text:

Nek Bail and Nek Mazlan play the violin. They learnt to play the violin when they were about 15 from a person who has now passed away....... His name is Laurie Ben Saran [Laurie bin Saran]. The violin is a traditional Scottish instrument brought to the islands by the Clunies Ross family many years ago ........ Not many people play the violin on the islands any more. We are learning about the violin and dancing so that our tradition is not lost for ever. ${ }^{19}$

In this narrative, the biola is clearly positioned as being part of traditional Cocos Malay culture with intergenerational patterns of transmission, even though it is described as a Scottish instrument with its introduction attributed to the Clunies-Ross family (a common story of origins, as discussed below). While the word 'violin' is used here rather than 'biola', it must be noted that this script was written by a schoolteacher for an audience of tourists who could understand English (for a critique of the use of English in educational contexts on Cocos see Bunce 2012). When speaking English, Cocos Malays use the terms 'biola' and 'violin' interchangeably, depending on conversational context and the origins of the interlocutor. Even so, the term 'biola' predominates in colloquial use. Nevertheless, the presentation of this narrative for tourists shows that the community on Home Island was clearly aware of the decline in the practice of biola and traditional dancing. Their articulation of this issue in collaboration with educators sent from the mainland gave it prominence in collective discourse.

\footnotetext{
${ }^{18}$ The number of tourists on the islands is usually quite low-probably around twenty a week if averaged out through the year, although there are high and low seasons-and most accommodation is on West Island, from where tourists can make a day trip to Home Island by ferry across the lagoon. ${ }^{19}$ Undated document from Home Island School, Cocos (Keeling) Islands, kindly provided by principal Ray Denholm.
} 
Some members of the community suggest that reasons for the decline in biola culture include the increasing influence of popular music at social events and the decrease of interest among younger generations for the study of traditional practices of performing arts. In a written account from 2003, Haji Adam (Rabuhu bin Anthony) stated that 'the Cocos Malay elders pass on traditions to the next generation, but few of the young are interested in performing traditional music and dance' (Anthony 2003: 150). In 2015, Haji Adam—who had recently become Chief Imam of Cocos-told us:

Because they don't want to perform this any more, the Cocos Malay culture, theyprefer to have guitar, at the wedding they have the guitar and Malaysian music and so on, they don't require biola or gendang or rebana. It's more people who are interested having guitar. (Interview, 21 July 2015)

This opinion was reflected by one father who recounted: 'The kids actually say, “I don't want to do the traditional dancing and the drums violin music, I want to do the DJ, play techno music," and the parents say, "okay, whatever you like"' (interview AnonymousB, 5 August 2015).

Action was deemed necessary to address the apparent decline in traditional cultural practices. In 2014, the Cocos Shire Council applied to the Australian Government's Indian Ocean Territories Community Development Grants Programme for funding to support the teaching of the biola to younger students, and they received a grant of $\$ 10,894$ (Australian dollars). ${ }^{20}$ The funded project was described as'Purchase of equipment to support CKI traditional music education and events'. ${ }^{21}$ The community's cultural organisation Persatuan Kebudayaan Pulu Kokos (Cocos Islands Cultural Organisation, known as PKPK) was able to purchase ten instruments from Perth. Several of these were electric violins, which were bought together with amplifiers (see figures 3 and 4). This purchase in many ways demonstrates that the biola occupies a dialectical relationship between tradition and modernisation in Cocos Malayaesthetic

\footnotetext{
${ }^{20}$ Minister for Infrastructure and Regional Development (Australian Government), 'IOT Community Development Grants Programme Delivered', Media Release JB050/2014, 6 June 2014, Internet: <http://minister.infrastructure.gov.au/jb/releases/2014/June/jb050_2014.aspx> (accessed 2 July 2018). 21 'Projects funded under IOT Community Development Grants Programme Round One', Internet: <http://regional.gov.au/territories/indian_ocean/files/OIT-DGP-Round1.pdf>, accessed 2 July 2018.
} 
sensibilities. When asked to explain the reasoning behind the choice of electric violins, one person responded: 'Because they're louder.' This transition in practice reflects the aesthetic desire for loud volume in biola performance (to be heard above other sounds). It also suggests the adaptability of Cocos Malay cultural practices to fit new aesthetic frameworks and expectations, and also perhaps indicates a desire to bring biola playing in line with electric guitars and other new instruments, to ensure its place in current music culture. ${ }^{22}$ During fieldwork in 2015, we heard that no children were learning biola; in fact, the beginners were actually all adults who already had grandchildren (interview Nek Mazlan (Colin bin Puria), 23 July 2015). These students were starting from scratch and making remarkable progress, taught by Nek Yusri. Almost five years later, though, Nek Yusri informed me in April 2020 that he had six students learning (acoustic) biola, including younger students, and that they met to practise three times a week.

Back in 2015, one student, Nek Sumilla (Dennis bin Mokta), had told us that he had been learning the biola for just two weeks (interview 29 July 2015). His skills had advanced quickly in that time; he demonstrated proficiency in posture and technique (figure 5), and was able to play a melenggok melody with a clear tone. When asked if he knew the tunes before playing, he affirmed: 'A bit. When people were playing biola I would watch.' Nek Sumilla described the learning process as follows: 'He [the teacher] sits with me like this; we watch his fingers; when he plays the biola we watch what he does with his fingers.' He also stated his longheld ambition to play biola: 'I've wanted to play biola for a long time but I didn't have an opportunity ... now I have the opportunity.' In describing the social relations that led to this program, he stated:

\begin{abstract}
[Nek Dayang] ordered some violins. When they arrived he advertised for people who want to study biola. We paid $\$ 50$ and off we went ........ My wife is really happy that I'm learning biola........She likes to hear the melenggok tunes, the old tunes. (Interview 29 July 2015)
\end{abstract}

A mixture of cultural pride, nostalgia, and aesthetic appreciation surrounds the practice of the biola in this particular domestic context. Yet the public advertisement of biola

\footnotetext{
${ }^{22}$ The string quartet Bond, which plays on electric instruments, was known to at least one of the islanders, and I was asked if I knew of this group.
} 
lessons, supported by a key community organisation, also appears to be a relatively new direction in Cocos biola practice. Since the mid-twentieth century biola practice was usually linked to specific families on the island, with the father-son chain of intergenerational transmission part of its mystique and prestige. Yet with the endangerment of this tradition on the islands in clear evidence, and with few children wanting to learn, this new community strategy appears the most logical approach. As Huib Schippers and Catherine Grant point out, 'single inspired individuals or small, motivated groups can play a remarkable role in maintaining or reinvigorating a tradition' (2016: 336). At the time of our fieldwork, we considered how the presence of adult students, rather than children, represented a fundamental change in transmission tradition: in previous eras, younger people would learn through long-term immersion in the practice, and usually in family environments. However, since this time, as reported to me in April 2020, younger students have begun to learn biola. The ongoing progress and results of this revitalisation project on Cocos will be interesting to observe in the future.

\section{How the Biola Came to Cocos: Emic and Etic Perspectives}

The rationale for establishing a programme of revitalisation usually relies on the construction of a historical narrative, or a discourse of cultural relevance for any particular practice, as articulated by the people themselves. While historical studies of Cocos have often drawn on archival texts and images produced by people of European descent, the voices and narratives of Cocos Malays are increasingly visible and audible in a number of projects that have documented oral histories. ${ }^{23}$ It was thus importantfor us to ask directly about the origins of the biola on Cocos during fieldwork in 2015 and 2016, and we heard many stories. Some informants told us that their ancestors passed knowledge of the instrument down to them; others theorised that one of the early Clunies-Rosses must have introduced it. ${ }^{24}$ For instance, Nek Bail described the biola as

\footnotetext{
${ }^{23}$ See, for instance, Hunt 1989 and Hobson 2008. Various archival holdings of recorded oral histories exist: for instance, the Cocos (Keeling) Island Indian Ocean Oral History Project is a series of interviews with Cocos Malays made by Ade I. Taiwo in 1985, on 32 sound reel tapes (around 558 minutes) held at the National Library of Australia (ORAL TRC 1922).

${ }^{24}$ John (Johnny) George Clunies-Ross, who lives on West Island and is the son of the last proprietor of Cocos, gave an account in line with this narrative; he speculated that 'the first mate on the Clunies-Ross
} 
being on Cocos 'before I was born' (interview, 20 July 2015). More pragmatic explanations about the material object divulged particularities about how individual instruments were maintained: they were ordered from Singapore, some via the Cable \& Wireless employees on Direction Island, or bought in Perth. Nek Bail stated that his violin came from his father, and that his father's instrument had come from Singapore (interview, 20 July 2015). The earliest video footage of performing arts on Cocos, from 1954, shows biola players; photographs from the National Library of Australia, the National Archives of Australia, and Home Island Museum all include biola players. When we showed these archival images to community members on Home Island, they reported the names of all the players. Some photos come from New Year celebrations at the Clunies-Ross house, where players would perform for hours on end, accompanying dances and also playing 'Auld Lang Syne' together with other instruments, including accordion (Clunies-Ross 2009: 226).

We were intrigued to find out whether any instruments had been made locally on Home Island and our enquiries drew blanks, until Nek Bail revealed that long ago he and two other men had attempted to make a biola from wood of the geronggang tree, but its poor quality of tone (probably due to the high density of the wood) discouraged any further experimentation, leading back to a preference for imported instruments. He recounted: 'Back then I worked with a man who used a stick to walk and I made abiola with him [and] got a tree, cut/sliced it, made a frame ... yes, we made them here. One of the people was Ebrik [?]; the other one was Laurie [Laurie bin Saran?]' (interview, 20 July 2015). On the other hand, Nek Yusri stated: 'No, we have never made them. Tuan John [John Cecil Clunies-Ross] bought them for us, ordered from Singapore' (interview, 23 July 2015). It seems that biola-making on Cocos was a shortlived experimental phase during the youth of Nek Bail (and possibly earlier), but that it was easier and more advantageous to order ready-made instruments from Singapore. However, it is significant to note that while many items central to asli Cocos Malay culture are made on the islands-boats, cuisine, and some clothes-musical instruments are largely imported. Like many cultural objects and practices on the islands, the biola is wrapped in layers of meaning that come from Cocos Malay narratives and perspectives; these

vessel was European and was allocated enough space that he could probably have a violin' (interview, 27 July 2015). 
often chime with etic academic understandings of cultural processes within this part of Southeast Asia, and sometimes diverge from them. ${ }^{25}$

While the last proprietor of the islands, John Cecil Clunies-Ross (known as 'Tuan John'), is known to have given a biola to particular players, we were told by members of the Cocos Malay community that they would periodically ask him to acquire new instruments when replacements were necessary. In traditional societies, the gifting of instruments to players by a patron brings with it a sense of social obligation; in Cocos, this kind of exchange probably created complications in a period of political transition and democratic transformation. Such a circumstance was noted by Pat Linford in her autobiographical account of her period of residence on West Island in the early 1970 s. $^{26}$ Linford implies that the cultural patronage bestowed by the Clunies-Rosses was a factor to be taken into account by members of the Cocos community when they made the decision to overturn traditional expectations and move to Australia, as can be seen in her description of the musical life of one Cocos Malay émigré:

\begin{abstract}
Kayser was ... known for his musical ability: he was reputed to be the best fiddler on the island, capable of double-bowing [sic] ${ }^{27}$ If he were doubtful about going to Australia it would be because of the obligation he felt to Tuan John because he had bought a fiddle specially for him in Singapore some years previously - it had cost Tuan John S\$30 and was worth every penny, by all accounts (about \$A10.00). (P. Linford 1994: 171-72)
\end{abstract}

While this comment about reciprocity appears to be her own speculation ('if ... it would be because...'), she nevertheless highlights the sense of obligation felt by a Cocos Malay musician who received gifts bestowed by a patron in this specific social context. In this way, it could be interpreted, the sourcing of instruments was connected to the

\footnotetext{
${ }^{25}$ Thanks to Jenny McCallum for the observations in the last two sentences.

${ }^{26}$ Her husband Robert J. Linford was the Australian government administrator of the islands, with a base on West Island; his role put him in an adversarial political position vis-à-vis the traditional rule of John Cecil Clunies-Ross. The Linfords actively articulated the Australian government's support for the Cocos Malay community during a politically turbulent time for the islands, and were instrumental inassisting Cocos Malays to migrate to the mainland.

${ }^{27}$ In this account, it is unclear precisely what Linford meant by 'double-bowing'; presumably she did not mean double-stopping (playing on two strings simultaneously), since this is an integral part of Cocos biola technique, and all players (as seen live and on video) are capable of it.
} 
extent of the patronage wielded by the ruling family, and their access to external resources that could be imported.

\section{Colonialism, Transplantation, and Material Culture}

The story of how the biola came to Cocos involves due consideration of the islands' complex political history. Originally uninhabited, the islands first appear in any known historical record with a description of their sighting by Sir William Keeling in 1609. Apart from brief maroonings of shipwrecked sailors, they remained unpeopled until 1826, when British merchant Alexander Hare established a settlement with a retinue of 99 Malay-speaking slaves. While these people spoke a common language, their ethnic and geographical origins were diverse: they came from Bali, Bima, Sulawesi, Madura, Sumbawa, Timor, Sumatra, Pasir-Kutai, Melaka, Penang, Jakarta, Cirebon, Banjarmasin, Pontianak, Tasikmalaya, and Kota Waringan (Bunce 1988: 43). In 1827, John Clunies Ross (a former associate of Hare) arrived with his wife and five children, mother-in-law, and fifteen others (for a list see Bunce 1988: 133), and founded with them a rival settlement on South Island. The Cocos Malays gradually left Hare, who left the islandsin 1831, and moved to Clunies Ross's base; this community then transferred to Home Island in 1834.

With coconuts and copra as the main industry, the Clunies-Ross family's regime existed for five generations (the surname becoming hyphenated from the fourth generation). Their system of rule controlled the Cocos Malay community's contact with the outside world, and this meant that Cocos Malay cultural practices and language became quite distinct from other parts of the Malay world. On Cocos, the head of the family was known as 'Tuan' (a term that equates to 'sir'; see Welsh 2015: 65n3); external observers sometimes romanticised the role of successive heads as 'kings of the Cocos' (e.g. Hughes 1950). The relationship between this autocratic figure and the community on Cocos, according to John Hunt, 'bore a number of likenesses to a traditional nineteenth[-]century Malay state' (1989: 1). According to the terms of an agreement signed by John Clunies Ross and twenty heads of families in 1837—which Hunt describes as a 'social contract' - the ruler was expected to provide a house, garden, and paid employment for each family in the community (1989: 5-6). ${ }^{28} \operatorname{In} 1857$

\footnotetext{
${ }^{28}$ Hunt writes: 'Their [the Clunies-Ross's] rule provided food, clothing, shelter and protection for all, under a system of total political and economic dominance by the family' (1989: 1). The political structure
} 
the islands were annexed by the British empire; this was actually a result of mistaken identity, since the naval officer involved was ordered to go to a different set of 'Cocos Islands', in the Bay of Bengal (Tarling 1959: 400-402). The rule of the Clunies-Ross family was recognised, and subsequently legitimised by Queen Victoria in an indenture of 1886 that granted the islands to the family in perpetuity (Hunt 1989: 7; United Nations Involvement with Australia's Territories 1975: 161-166).

In the early twentieth century there were reports of slavery on the islands. After remarks about his style of rule were made by John Sidney Clunies-Ross during a visit to London, a campaign for a formal investigation was championed by the Anti-Slavery and Aborigines Protection Society in the late 1930s, although this process was interrupted by the death of a major British campaigner and the outbreak of the Second World War. ${ }^{29}$ During the Second World War the islands were a major base for the Royal Air Force, and in August 1944 became the target of a Japanese bombing raid. In the wake of the war, the management of the Clunies-Ross Estate considered that the local economy and resources could not support the population of the islands, and with an agreement with the British Colonial Office it controversially relocated more than three-quarters of the community to Christmas Island and Sabah, Borneo, gradually reducing the population of Home Island from 1,802 in 1948 to just 374 by the beginning of 1952 (Hunt 1989: 126).

Following the transfer of sovereignty from the United Kingdom to Australia in 1955 there were some inspections by the Australian government in the late 1950s, but conditions on Home Island were left largely to the administration of the Clunies-Ross Estate. With increased Australian involvement in the islands and interaction with the Cocos Malay community, however, and in the context of United Nations pressure for decolonisation worldwide, Cocos came to national and international attention in 1972.

\footnotetext{
in Cocos has been noted to resemble, albeit on a smaller scale, the Brooke family's regime in Sarawak, Borneo, which existed from 1841 to 1946 (Dutt 1981: 477). A major difference on Cocos was that members of the Clunies-Ross family married Malay spouses in the late nineteenth century, and occupieda liminal cultural space between colonial rulers and colonised populations, to the extent that in the 1890s British colonial authorities even questioned their level of 'civilization' and their 'authority' to rule over the local population (Papers Relating to the Cocos-Keeling and Christmas Islands 1897: 50). In subsequent generations, the heads of the family gravitated away from a Cocos Malay cultural identity, but still used the symbolic trappings of Malay royalty, such as yellow sails on their boats (Hunt 1989:137). ${ }^{29}$ Papers of the Anti-Slavery Society: Cocos Islands (1937-1941), MSS. Brit. Emp. s. 22 / G360, Bodleian Library, Oxford.
} 
The way that John Cecil Clunies-Ross ran the islands-including the minting of his own plastic currency, with which workers were paid and with which they could buy goods locally-was the focus of intense public debate and political controversy during the 1970s, both within Australia and internationally. From this decade, numerous Cocos Malays emigrated with the assistance of the Australian government, first to Christmas Island, then to Western Australia (Hobson 2008). Following intervention by the United Nations the islands' freehold was bought by the Australian government in 1978, bringing the rule of the Clunies-Ross family to an end (United Nations 1978). The Cocos Malay community participated in an Act of Self-Determination vote in 1984, under U. N. supervision, and its 261 eligible voters opted overwhelmingly for integration with Australia rather than independence or self-determination (Tahmindjis 1985). ${ }^{30}$

Given the long period in which the Clunies-Ross Estate had an impact on cultural life in the islands, through the control of transportation and access to the outside world, examination of their shipping records and other archives can shed a great deal of light on material culture and the history of cultural life in the islands. Orders from merchants in Singapore and Jakarta in the early twentieth century reveal details of the importations of many kinds of musical accessories. The supply ship came twice a year, and the listing of goods in the large orders appears to reflect careful consideration of the community's material needs. These archives, which contain all the correspondence regarding their orders with their agents first in Batavia (Jakarta) and then in Singapore, also show that Cocos Malays travelled to and from these ports. The estate regularly ordered copies of the Qu'ran (including romanised and, remarkably, English versions) and books of zikir for the Malay community, gramophone needles and gramophone records, and instruments including rebanas and mouth organs; there are many orders for violin strings, violin bows, and blocks of 'cheap violin resin [sic]'.31 However, it is

\footnotetext{
${ }^{30}$ There were 229 votes for integration, 21 for free association, nine for independence, and two informal votes (Mowbray 1997: 391).

${ }^{31}$ For example, a request for supplies dated 22 January 1922 sent from Cocos to Singapore asks for ' 6 Sets of Violin Strings (E.A.D.G.)', as well as 18 Korans and '12 Books - "Zekir Maulud" (Written in the Arabic)'; the latter refers to books of zikir (dhikr) texts for Maulud Nabi (Accounts and correspondence,Caldbeck MacGregor and Company with J S Clunies Ross, 1921-1933', National Archives of Australia, A9752/116, Part B). In 1926, sheep's hide 'for tambourine' (rebana) was ordered besides '12 complete sets Violin strings' ('Invoices from Caldbeck MacGregor to J. S. Clunies Ross', National Archives of Australia, A9752/1 / 115, Part C). In 1928-1932, several sets of mandoline strings were obtained, multiple violin strings, as
} 
interesting to note that while violin accessories were ordered along with all other supplies, violins themselves are never listed. This could perhaps suggest that violins were considered relatively fragile, or that they were special requests that were carried personally. Interestingly, an order from 31 July 1939 distinguishes between E strings made of 'wire' (with 15 requested), and A strings made of gut (5 requested). The apparently deliberate specification of gut is a curious point to consider, but it is the only time gut strings appear in the shipping records. In the same accounts it appears that on 7 August 1940 wire A strings were once again ordered, along with E strings and rosin. ${ }^{32}$ In August 1944, there was a Japanese bombing raid on Cocos which resulted in the deaths of two people and the destruction of 27 houses. John Sidney Clunies-Ross also subsequently died of a heart attack, and the British military took over control of Home Island. The interim administrators made an inventory of 'Effects destroyed by enemy action'; this was a long and detailed list of contents within the houses that had been destroyed. Losses of possessions included a violin in the house of Nada at 19 Piccadilly Road, and in two other houses a gramophone with records and an accordion ('Cocos Islands: emergency organisation', National Archives of the United Kingdom, CO 273/673/9). Following John Cecil Clunies-Ross's return to the islands on 6 July 1946, orders were made later that year for violin strings (10 of each string) and six violin bows - as well as six mouth organs, a dozen boxes of gramophone needles, 12 Korans, 12 copies of Surat Berzanzi (Zikir Maulud), and incense. ${ }^{33}$ The order was probably made by the estate manager 'responding to Kampong requests' (Hunt 1989: 99). While the shipping records give a fascinating picture of material culture on the islands, they still tell us little about practice-apart from the fact that strings and bows were regularly in need of replacement-and this must be considered in dialogue with the kinds of

well as Malay and English gramophone records (including many instance of 'Malay Dance Records'), boxes of gramophone needles, rebanas, a Robinson Piano Company accordion, Korans, and books of Zikir Maulud ('Invoices from Caldbeck MacGregor to J. S. Clunies Ross', National Archives of Australia, A9752/1 / 115, Part A). An order for supplies sent from Cocos to Singapore on 1 August 1938 included ' 3 cheap violin bows', three dozen violin strings, and ' 12 blocks cheap violin resin [sic]', while an order from 20 November 1938 included '1 cheap violin bow' ('Caldbeck MacGregor - Accounts and indents and correspondence', National Archives of Australia, A9752 / 119).

32 'Caldbeck MacGregor - Accounts and indents and correspondence', National Archives of Australia, A9752 / 119.

${ }^{33}$ Supplies required' (1946-47), National Archives of Australia, A9752 / 138. 
ethnographic data discussed earlier. However, we can speculate that the regular appearance of bows in the orders suggests a number of possibilities: that they either served a growing body of biola players, that they were played with sufficient strength to wear them out relatively quickly, or that the tropical climate contributed to the rapid disintegration of the hair. A combination of the last two factors seems to be the most likely explanation. Rehairing the bows would have involved importing the hair of horsetails, which was perhaps relatively difficult to obtain.

\section{Other Histories of Origins: A Naturalist's Report and a Natural History Perspective}

It is clear that the idea of the biola being introduced to the islands by the CluniesRosses-or at least its practice being sustained by them through the bestowal of patronage and introduction of Scottish repertoire-is a consistent subtext within discourse about life on the islands. This theory is reinforced through traditional methodologies of research into historical archives. Yet while it has been more or less taken for granted that the family was responsible for bringing the instrument to the islands, or for introducing Scottish repertoire, this assumption is nonetheless problematic: it denies or at least minimises the agency of the players themselves.Given the proliferation of biola practice across the Malay-Indonesian archipelago, it seems likely that the biola or at least knowledge of its practice came to the islands with the very first arrivals from 1826, before the arrival of John Clunies Ross the following year.

An unexpected discovery in the archive of the Royal Botanic Gardens in London supports this theory. The evidence comes from a curious anecdote related by naturalist Henry Nicholas Ridley, who visited Cocos in 1890. Ridley travelled to the islands at the behest of the colonial government in Singapore to make a periodic inspection on the conditions of the Cocos community; he included a chapter on Cocos in his expansive and wide-ranging (still unpublished) autobiography, which appears to date from between the world wars. During Ridley's two-day visit to Cocos in 1890, an elderly Cocos Malay man requested to speak to the doctor accompanying Ridley, as his eyesight was deteriorating. ${ }^{34}$ Ridley states that this Cocos man had been on the islands since the time

\footnotetext{
${ }^{34}$ Ridley recounts: 'There was very little sickness of any kind on the island. As we were walking about one very old man stopped us and asked for the doctor who was with us and also enquired what ailed him. The old fellow who was living on the island in Hare's time (i.e. for two generations) complained that he could not see a ship at a long distance as he could when he was a boy. The doctor told him that few people over
} 
of Alexander Hare ('i.e. for two generations') and implies that he was over the age of eighty. ${ }^{35}$ He writes:

The old man told us some tales of the eccentric Hare and Ross told us some more. ['Ross' refers to Ridley's host, Andrew Clunies Ross, a son of George Clunies Ross (the third hereditary head of the family on Cocos) and his first wife Inin (who was Cocos Malay)]. ${ }^{36}$

The original Ross was a sailor who discovered the island and decided to settle on it and grow coconuts, so went off to the Cape to obtain slaves for planting. While he was gone Hare who was seeking some corner of the globe where he could settle uninterfered with by other people, came to Cocos [in 1826] and settled down with a large harem and a library, on one island, and when Ross returned, he settled on another nearby with his slaves and Malay coolies. Now at low tide it was quite possible for Ross' men to wade across to Hare's island and make love to the ladies of the harem. To induce them to keep away Hare presented them with a fiddle and two sheep. They played on the fiddle till it was broken and ate the sheep and returned as before. Eventually Hare was so vexed

eighty could do so and an arrangement was made to get him some spectacles.' Henry Nicholas Ridley, 'Visits to Cocos and Christmas Islands', Ms., n.d., Royal Botanic Gardens Library and Archives, HNR/5/15, 10.

${ }^{35}$ Ibid. In 1885, a British colonial official cited the 'social contract' of 1834, and noted that two of the signatories were still alive: 'PA BESSAR (Basîr) and PA RAH' (Birch 1885: 17). A photograph taken during that visit has a caption that indicates that one of the people in the group was the oldest man in the settlement, named 'Neh [Nek] Basir' (Birch 1885: appendix XIV, photograph no. 12). It seems that the system of Cocos Malay teknonymy was not understood here and that the names Pak Basir and Nek Basir refer to the same person. Nek Basir, who was born in Melaka in 1805, came to Cocos with Alexander Hare in 1826, and had papers from 1820 proving his identity (Birch 1885: 16). It is possible that Ridley's informant in 1890 was one of the two men described in 1885.

${ }^{36}$ Several members of the Clunies-Ross family married Cocos Malay spouses. George Clunies Ross (who governed the islands from 1871 to 1910) and five of his brothers married Cocos Malay women(Hunt 1989: 9); the parents of these men, in turn, were John George Clunies Ross (who ruled Cocos 1854-71) and his Javanese wife S'pia Dupong (Gibson-Hill 1952: 84). The wife of the ruler had considerable social influence on the islands: for instance, Inin (1850-89)—the first wife of George Clunies Ross-was described as a matriarch of the community who 'stood as law for the women, and ruled them by her example' (Wood-Jones 1912: 35). 
that he put the harem and library on a ship and sailed for Sumatra to seekpeace, but the ship was never heard of again and was supposed to have been lost at sea.

Hare's slaves and coolies however remained on the atoll and joining Ross formed part of the present inhabitants. (Henry Nicholas Ridley, 'Visits to Cocos and Christmas Islands', Ms., n.d., Royal Botanic Gardens Library and Archives, HNR/5/15, 11; emphasis added)

Several elements of this story - the rivalry of Hare and Ross-are well known in the history of the islands. Yet most importantly, it seems clear that Cocos Malays already knew how to play the biola. One could speculate that this story's reference to the fiddle being played 'till it was broken' may imply the breaking of strings as much as anything else. Although the tale speculates that the ship was lost at sea, it is known that Hare left Cocos in March 1831 and apparently settled for a while in Bengkulu, before disappearing without trace (R. Linford 2009: 56, 59-60; Gibson-Hill 1952: 96). One wonders how reliable the recollection of this elderly informant may have been, and the extent to which poetic retellings had adorned the story. Yet in this small and geographically isolated community, key historical events stand out in memory: in 1896, for instance, Arthur Keyser attested that 'Some of the old people still recollect the visit of H.M.S. "Juno" in 1857' (Papers Relating to the Cocos-Keeling and Christmas Islands 1897: 88), and in 2015-2016 we found that people had vivid memories of the Queen's visit in 1954. It is not difficult to apply this sense of reliable long-term memories to the elderly Cocos Malay man who informed Ridley in 1890 of a tale from the late 1820s, and that Hare's present of 'a fiddle and two sheep' stood out in the memory of one of the original settlers.

Besides drawing on evidence from traditions, memories, intraregional comparisons, and archival anecdotes to create a framework for the history of the biola on Cocos, it is important not to ignore language, names, and natural history. Eliot Bates remarks that 'much of the power, mystique, and allure of musical instruments ... is inextricable from the myriad situations where instruments are entangled in webs of complex relationships-between humans and objects, between humans and humans, and between objects and other objects' (2012: 374). These complex relationships are clearly evident in the transplantation of people and cultural systems across the ocean to Cocos, and the plantation economy of the islands in which people's gathering and 
processing of coconuts resulted in profits that led to the exchange of many kinds of material goods, including the biola. Yet the biola was connected in a fascinating way to the islands - as far as is known, not seen in any other part of the Malay world-through the embedding of its symbolism within knowledge of the islands' ecology.

It is perhaps a truism to state that communities create connections to place through the act of naming, and that the taxonomic imperative faced by any migrant group - to name and describe a new environment-is a mechanism by which meaning is constructed and familiarity fostered. One of the local delicacies regularly collected, cooked, and consumed on Cocos is the sea snail known as kepala biola; its biological name is Turbo lajonkairii and it is known in English as 'turban snail'. In Cocos Malay, this evocative term literally means 'head of the violin', due to the close resemblance of the shape of the shell to a violin scroll (figure 6). The snail's name appears to be unique to Cocos Malay: it does not seem to be used outside the community, a distinct ethnolinguistic group both on the islands and in diaspora. ${ }^{37}$ Kepala biola aregathered on the reef that surrounds the small coral atoll; the flesh is extracted, prepared, and cooked to make sumptuous dishes that are high in cholesterol (figure 7). ${ }^{38}$ Theyare served at feasts that have traditionally featured dancing and other forms of entertainment, often accompanied by biola players. Empty shells washed up on beaches, or discarded by cooks, become the homes of the largest hermit crabs inhabiting the coastline and the forests. These crabs in turn are collected by fishermen who break open their shells, to use the crustaceans as bait. Broken remnants can be seen scattered beside popular fishing sites, on shores and jetties. A small disc (operculum) that the snail uses as a trapdoor to the shell's circular opening is discarded; these attractive objects accumulate in and by the water after their separation from the organism, are spotted and collected by residents and visitors, and often used as ornaments.

\footnotetext{
${ }^{37}$ Even in the closest community that speaks another variety of Malay, on Christmas Island, the same shell is known as siput mata lembu (cow's eye shell), as the snail's trapdoor evokes a bovine resemblance. Thanks to Nek Su (Ramnie bin Mokta) for this insight.

${ }^{38}$ Virginia Orr Maes writes: 'Abundant in cracks and on sides of reef-rock blocks near the fore part of the seaward reefs, passes, and rocky parts of the northern lagoon, it was used as food by the local people' (1967: 106). Today kepala biola is boiled for three hours with onion, garlic and oil, then cooked with vegetables including beans, broccoli, capsicum (pepper), and chillies. Prior to the widespread availability of fresh vegetables on Cocos, people cooked a soup-like stew with kepala biola and rice. Ayesha

(Jeannette Young), personal communication, 10 May 2019.
} 
The kepala biola snail is thus embedded within the rhythms of Cocos Malay life; local knowledge avers that the luxury dish it produces must nonetheless be consumed with moderation, as an excess can contribute to gout. The reference to biolas in the nomenclature of this organism, its iconic status as a dish eaten at celebrations, and its use as an ornament are phenomena that provoke many questions about the symbolism, social functions, and histories of the biola in Cocos Malay culture. The name given to this mollusc on Cocos does not seem to exist for any similar organism in Indonesia, where the community's ancestors came from. Is it possible, then, that when the earliest groups of Cocos Malays on the islands were forced to locate and identify immediate means of sustenance, they named this animal after an instrument that they already knew? The earliest written reference to the name kepala biola appears to be from the British medical doctor Carl Alexander Gibson-Hill, who was based on Cocos for ten and a half months in 1941, and subsequently published extensively on the history, natural history, and culture of the islands. He wrote in 1946 that one of the three shellfish commonly eaten on the islands was 'a gasteropod [sic] known as Siput Kĕpala Viola (from its shape) [Turbo (Senectus) lajonkairii Desk.], which is very plentiful on the barrier and is used for making soup' (Gibson-Hill 1946: 20; Gibson-Hill 1947: 193). ${ }^{39}$ How far back the local name extends is unknown. Although linking this snail's name to the prior presence of the biola among the naming community may seem conjectural and too tenuous a leap for the firm establishment of a chronological narrative, the case of the kepala biola could

\footnotetext{
${ }^{39}$ The earliest biological description of the species, without mention of the local name, is Deshayes 1839 (as cited by Maes 1967: 106). There are several species that are close in appearance. R. Tucker Abbott attributes the native name 'Kĕpala Viola' to the species Turbo (Marmorostoma) argyrostomus (1950: 70); however, Virginia Orr Maes (1967: 106) states that this scholar erroneously recorded young examples of T. lajonkairii. Alistair Welsh (personal communication, 5 December 2018) stated that he remembered some decades previously, when he was working on the islands as a government interpreter, being taken to collect kepala biola near Horsburgh Island. Over a dozen boats went on this trip. There were two species that were almost indistinguishable but he was told that one of them was not kepala biola, and gradually he began to see the difference.

There are other examples of local names being bestowed on shells in Cocos. FredericWood-Jones noted in the early twentieth century that the second Clunies Ross to rule the islands, John George Clunies Ross (1823-1871) was passionate about natural history; for his amateur medical knowledge 'and forhis patient researches into the natural history of the islands, he received the native title of Tuan-pandai, or "the learned one," and to this day a cowry shell, in whose finding he took special delight, is called siput tuan (the master's shell) by the natives' (Wood-Jones 1912: 30).
} 
be compared to the North American fiddlehead fern, whose name may indicate a similar story of prior encounter and symbolic naming. ${ }^{40}$ When we asked Nek Yusri whether there was a connection between biola and kepala biola, he speculated that perhaps the instrument had been named after the snail (rather than the other way around). This comment seems to emphasise the story of migration to the islands and inscribe the biola within a Cocos Malay narrative of natural history, as well as underscoring the priority of nature over objects of material culture. Given that the nominal linkbetween the snail and the biola has, over time, become absorbed into everyday life, the story of how the animal was named seems lost in the mists of time and must remain conjecture.

\section{Further Historical Dimensions: Etic Observations of Performance}

Most written evidence of the historical use of the biola on Cocos come from descriptions of performance. From the late nineteenth century until today, reports by visitors to Cocos have often invoked the imagery of a fiddle accompanying local dances, whether presented in sharp focus or in passing, as a symbol of the intertwined histories of Scottish and Malay cultures on the islands. There are relatively few descriptive textual accounts of the performing arts on Cocos before the 1890s, apart from Charles Darwin's 1836 description of a dance and song (see Irving forthcoming), but from that decade onwards a range of archival evidence attests to the continual and habitual use of biola on the islands. While all of these accounts were written by British observers, and one North American, these authors seem to have been at pains to locate and describe cultural practices that were recognisable to them, and with which they could feel an affinity. ${ }^{41}$ When HMS Æolus visited Cocos in 1896, George Clunies-Ross invited the captain and officers for dinner and entertainment on the last night of their stay (30

\footnotetext{
${ }^{40}$ Although this is a longstanding traditional name for the fern, there is little documentation of the history of its use. See the poem 'Fiddlehead Fern' by Dudley Laufman which muses on this question, beginning 'Which came first, / the fern or the fiddle?' (Laufman and Laufman 2009: 28).

${ }^{41}$ However, they sometimes demonstrated antipathy, as can be seen in an account from an official annual visit for the Colonial Report of 1898. R. J. Farrer, a civil servant from the Straits Settlements, wrote of a dance performance (which may have included biola even though it is not mentioned) that 'the music is of the same abominable character as that of the Straits, but the drum parts, in deference either to the feelings of Europeans or to the age of the instruments (which is more probable) are not played with such lamentable energy' (Cocos-Keeling and Christmas Islands 1899: 16). For a critique of nineteenth-century British discourse on Malay music, see Irving 2014.
} 
June). By this stage the ruling family was residing in a large house in 'baronial style' that had been built in 1893 (Hughes 1950: 99; Hunt 1989: 17). Still standing today, it has a large room on the ground floor that served as the ballroom. The official report by Arthur Keyser (Collector and Magistrate of Jelebu in Negeri Sembilan on the Malay peninsula) describes the entertainment as follows:

In the evening the natives came to the house in large numbers. Their own musicians played, and they danced native dances. The dances were reels and old Scotch figures. These were performed with much solemnity and grace by men and women together. The latter wore no veils, and behaved exactly as Europeans would do, the former discarded their caps and danced bare-headed. Groups of spectators sat about on the floor, unheeding the numerous dogs which wandered about among them. All partook of whisky as refreshment. The scene was more English than Malay. (Papers Relating to the CocosKeeling and Christmas Islands 1897: 78-79) (emphasis added)

It is significant to note that the 'native dances' mentioned by Keyser in one sentence are explained as 'reels and old Scotch figures', if the report is taken at face value; another way of reading it could be a description of subsequent events: a succession of Malay and then European dances. However, it is clear that the performers 'owned' their dances, and the kinds of 'dansa Cocos' observable today are often remarked on by observers to be similar to 'Scottish' practices. ${ }^{42}$ The comments about the 'English' rather than 'Malay' character of this evening in 1896 appears predicated on the lack of headdresses, and the presence of dogs and alcohol. Although Keyser does not mention the instruments used when 'their own musicians played', it can be assumed that 'reels' involved the accompaniment of a biola (and possibly drums).

Justice Andrew J. Leach visited Cocos from the Straits Settlements in July 1897, in an official capacity to make an annual report, and 'had an opportunity of witnessing the dances referred to by Mr. Keyser'; he refers laconically to 'a dance performed by men and women' in which 'a violin strikes up a sort of double shuffle air' (Cocos-Keeling and Christmas Islands 1897: 21). Coincidentally, Canadian-American sailor Joshua Slocum

\footnotetext{
${ }^{42} \mathrm{~A}$ Norwegian scholar commented to me at a conference in 2017 that one of the Cocos dances appeared similar to a Norwegian folk dance.
} 
was in Cocos at the same time, during the course of his famous solo circumnavigation, and corroborates Leach's report in his lyrical narrative Sailing Alone Around the World:

On the 22d of July [1897] arrived H. M. S. Iphegenia, with Mr. Justice Andrew J. Leech [sic] and court officers on board, on a circuit of inspection among the Straits Settlements, of which Keeling Cocos was a dependency, to hear complaints and try cases by law, if any there were to try........ If there is a paradise on this earth it is Keeling. There was not a case for a lawyer, but something had to be done, for here were two ships in port, a great man-of-war and the Spray. Instead of a lawsuit a dance was got up, and all the officers who could leave their ship came ashore. Everybody on the island came, old and young, and the governor's great hall was filled with people. All that could get on their feet danced, while the babies lay in heaps in the corners of the room, content to look on. My little friend Ophelia danced with the judge. For music two fiddles screeched over and over again the good old tune, 'We won't go home till morning.' And we did not. (Slocum 1900: 217-218)

The song to which Slocum refers is widely known to be sung to the tune 'For he's a jolly good fellow' (deriving from the French folk melody 'Marlborough s'en va-t-en guerre', popular in the eighteenth century). The choice of the term 'screeched' is noteworthy; this verb appears to capture the cracking tone of heavy friction between the horsehair of the bow and the strings, as heard in today's performances. The violin is held low, and the bowhair is tightened to high tension, with the weight of the arm increasing the pressure and friction on the strings.

One of the most popular contexts in which dances were performed to the accompaniment of biola was for weddings, which featured multiple genres. Gibson-Hill gave a detailed description of dance performances that took place at wedding celebrations, to the accompaniment of biola:

The afternoon ceremony was generally followed by an evening entertainment. This was normally at the house of the bridegroom. It took the form of one of the usual kampong entertainments-a Dansa or a Selon. These might also be staged at any time, to celebrate a personal event, when a family thought that they could afford it........Inside the house three of the older men of the kampong, lead [sic] by the head man, played on antique fiddles. The Dansa was the more popular of the two entertainments. The music consisted 
largely of distorted versions of old highland tunes, to which couples, men and women, danced a form of Sir Roger de Coverley, with a number of interpolated movements. A single dance lasted about ten minutes, and usually exhausted the majority of the participants. The spectators generally kept time to the music by clapping their hands. Sometimes the sequence of dances would be broken by a scarfdance (Mĕlenggok) performed by two of the men. (Gibson-Hill 1947: 173)

The description of 'antique fiddles' suggests that these were not new instruments acquired from Singapore, but perhaps violins that had been kept in families by these 'older men', or for more than one generation. The reference to 'distorted tunes' highlights the recognition of melodies, but those that had been adapted to Malay aesthetic sensibilities. It is unclear how many weddings Gibson-Hill observed in the course of his 1941 stay on Cocos, although the population was much larger at thatstage, before the emigrations of 1948-1952, and weddings were more frequent.

Performances were also given in honour of visitors, as remains the case today. In 1948 M. J. Ross, Commanding Officer of HMS Hart, made a description of a performance given to welcome the Governor of Singapore:

In the evening [Saturday 17 April 1948], Mrs. Clunies-Ross gave a dinner party to the Governor to which my First Lieutenant and I were invited. The other officers and European residents were invited in after dinner, and a most remarkable evening's entertainment was staged........ Proceedings started before dinner with children dancing. The dances were similar to Malay 'rongging' [sic] - graceful but rather dull and as performed by these youngsters, very solemn. The children were gradually replaced by the elders and the dancing changed to a mixture of Malay and Scottish, in which the Scottish element gained the ascendant as the evening advanced. Many of the tunesperformed by four venerable fiddlers and some beaters of drums-were easily recognisable Scottish Airs........ The dancers all performed with enthusiasm but the prize undoubtedly went to the 'lads of the village'. Their (men only) dances, based on the light footed Highland dances, were performed with great energy and skill, and a vast amount of noise from the metal-bound shoes. In the particular setting the result was most effective. (M. J. Ross, Report on a visit to Cocos and Christmas Islands, 6 May 1948, in Cocos 
Islands: Emergency Organisations, National Archives of the United Kingdom, CO $537 / 3656)^{43}$ (emphasis added)

It is striking to note the difference between Gibson-Hill's description of 'distorted versions of old highland tunes' and Ross's reference to 'easily recognisable Scottish Airs'. While these comments indicate varying musical or aesthetic expectations, they also reveal certain cultural prejudices and, in the case of the comment about 'distortion', an essentialism surrounding the exact reproducibility of Scottish Highland music.

The earliest known archival video footage of Cocos Malay music and dance, albeit without sound, dates from 1954 and records the occasion of Queen Elizabeth II's visit to Cocos on 5 April, en route from Western Australia to Sri Lanka (then Ceylon). This event was reported throughout the British Commonwealth through Movietone news, and a reporter's commentary was added with stock audio recordings. ${ }^{44}$ Lengthier (silent) footage from the British Pathé archives, clearly made by the same videographer, shows that the Queen's progress through Home Island was preceded by two men dancing a silat, accompanied by a gendang and two biolas (figure 8$).{ }^{45}$ While we only ever saw biola performances given with the player seated (on Cocos or in Katanning), it seems that the instrument has also been played as a processional instrument, with the player walking as he performs, as seen in the video of the Queen's visit. The biola is usually used only in secular contexts, and this performance of the silat, recorded on film, is the only archival evidence seen in the course of this research of non-secular contexts involving biola, if the supernatural contexts of silat are taken into account. The procession went on to Oceania House, the residence of the Clunies-Ross family, before entertainments were given outside under a pavilion, with two men dancing the melenggok, accompanied by gendang and biola (figure 9), and finally a selong. 46

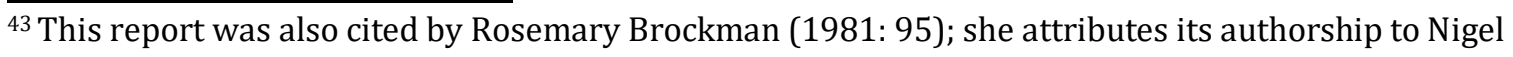
Abercrombe. However, an earlier source, quoted here, indicates that the author was M. J. Ross. ${ }^{44}$ British Movietone, 'Royal Tour. Queen at Cocos Islands and Ceylon', 22 April 1954, availableat: <http://www.aparchive.com/metadata/youtube/ab97b21b8f8c4f35a81cd7b2a23e83ed> (accessed 3 April 2020).

${ }^{45}$ British Pathé, 'Queen in Coco's Isles [sic]', available at: <https://www.britishpathe.com/video/queenin-cocos-isles/> (accessed 3 April 2020).

${ }^{46}$ Two days prior to her visit, the Adelaide periodical The Mail Digest had pondered about the kinds of performances that would greet the Queen, remarking on a mix of Malay and Scottish cultural traditions on
} 
Other holdings in public archives fill in the various stages of the biola's history on the islands. ${ }^{47} \mathrm{~A}$ collection of photographs taken by the late Daphne Clunies-Ross, now held at the National Archives of Australia, include images of performing arts and celebrations on Home Island. One of these photos (figure 10) shows two biola players, Nek Bail and Nek Yusri, performing on a festive occasion in the 'Club Lama' (the old club building known as the Cocos Club). In 1982, during the transitional period between the Australian purchase of the islands' freehold (1978) and the vote for Self-Determination (1984), Senator Tom McVeigh, then Minister for Home Affairs and the Environment, visited Cocos and was received in grand style by the local community. The official photographs from the ministerial visit included scenes of music and dancing. McVeigh participated in the dancing held on this occasion and appears to have taken a keen interest in the biolas played there; the biola players were Nek Yusri in the foreground and Nek Mazlan behind him (figure 11). ${ }^{48}$ Although what may have been discussed is not known, it seems that the power of biola performance attracted considerable interest from a senior representative of the Australian government, and that the government was respected and received by the community as a new symbol of authority.

\section{Conclusion}

Wherever human communities have migrated in the modern world, they have taken with them musical instruments, or knowledge of instruments. The physical fashioning and sonic animation of musical instruments are recognised as primary means by which humans make sense of their environment, communicate with it, or-in the case of a transplanted community-demarcate the boundaries of a new social-temporal reality. Instrumentalists can iterate in real time their sense of place and belonging, or their connection to a distant point of origin, by means of performances that are intended for themselves, members of their own community, others, as well as the supernatural. The

Cocos, and stating: 'When the local orchestra goes into action, Malay dirges are lightened with snatches from "Cock o' the North" or "A Hundred Pipers." During wild island dances Malay kronchongs often give way to foursome reels which go on for hours' ('Queen to Meet a Brown Mr. McTavish' 1954: 51).

${ }^{47}$ There are also numerous photographs and video recordings made by Cocos Malays and held in their private collections. We were privileged that some of these were shown to us and shared with us.

${ }^{48}$ In the next photo McVeign takes the biola of Nek Mazlan into his own hands and appears to be examining it. Thanks to Nek Su (Ramnie bin Mokta) and Ayesha (Jeannette Young) for their assistance in identifying the players. 
use of instruments, broadly speaking, can be influenced by cultural factors including theological doctrine or cosmological order, religious ritual, gender roles, and social expectations. As Kevin Dawe has observed, 'musical instruments are as symbolic and emblematic of peoples and of places as any other musical phenomenon' (2012: 274). The history and tradition of the biola in the tiny and remote community on Cocos raises many questions about the transplantation of culture and the way that the symbolism of instruments becomes transformed in isolated communities.

In discourse about Cocos, the picture of intercultural hybridity presented by Malay-speaking Muslims playing Scottish jigs has loomed large as a potent symbol of the legacy of feudalistic colonialism, while the 'Scottish' fiddling practice on the islands has been the backdrop to critiques of the Clunies-Ross influence on Cocos Malaylife. However, the biola was probably practised by the ancestors of the Cocos Malays in different parts of the Malay-Indonesian archipelago long before the time before anyone arrived on Cocos. The transplantation of biola to Cocos arguably represents continuity in tradition, and not a rupture or break of any kind. Yet these traditions evolve: on Home Island, the gradual reduction in the number of players mobilised community organisations such as PKPK and the Shire Council to attempt to bring the biola to a wider social constituency. This has resulted in new aesthetic frameworks and techniques, with the electric instrument, and patterns of pedagogy that are not restricted to male children of families that maintain a performance tradition, but open to the broader community. The traditions and practice of the biola play a mediating role in linking current events to a sense of historical continuity and to the upholding of traditions; as such, they are strings across the ocean that connect the Cocos Malay community to their relatives in the diaspora and to their ancestors who settled in and lived on the islands.

\section{Acknowledgments}

This study was supported by Australian Research Council Discovery Project DP150103204, 'Malay Music and Dance from the Cocos (Keeling) Islands', based at the Melbourne Conservatorium of Music, the University of Melbourne, 2015-2019. The results of this study were written up at the Institució Milà i Fontanals de Recerca en Humanitats-CSIC, Barcelona, in 2019, following my move here as an ICREA (Institució Catalana de Recerca i Estudis Avançats) Research Professor. Thanks must go to all 
people from the communities on the Cocos (Keeling) Islands and in Katanning who participated in this study or supported it in other ways, especially Nek Bail (Alpan bin Puria), Nek Mazlan (Colin bin Puria), Nek Yusri (Zainal bin Wallie), Haji Adam (Rabuhu bin Anthony), Nek Sumilla (Dennis bin Mokta), Nek Tiara (Woren bin Dedian), Ray Denholm, Pak Azi (Ozzy bin Macrae), Nek Su (Ramnie bin Mokta), Ayesha (Jeannette Young), John (Johnny) George Clunies-Ross, and two anonymous informants. I would especially like to thank Jenny McCallum for her collaboration in the field and her indispensable work in translating from Cocos Malay to English, as well as for her participation in the Discovery Project as a whole. I am grateful to John Hunt, Nicholas Herriman, Monika Winarnita, Alastair Welsh, Michael Laffan, Margaret Kartomi, Brigitta Scarfe, Henry Stobart, Julia Byl, and Jim Sykes for their insights, advice, and input over the course of this study, to the two anonymous readers of this article for their detailed comments and suggestions, and to Joanne Byrne for permission to use her map. I would also like to thank Gary McPherson and Jane Davidson for their support of this project.

\section{References}

Interviews

Anonymous A

Anonymous B (5 August 2015)

Nek Bail (Alpan bin Puria), 20 July 2015

Nek Mazlan (Colin bin Puria), 23 July 2015

Nek Yusri (Zainal bin Wali), 23 July 2015

Haji Adam (Rabuhu bin Anthony), 21 July 2015

John (Johnny) George Clunies-Ross, 27 July 2015

Nek Sumillah (Dennis bin Mokta), 29 July 2015

Ray Denholm, 3 August 2015

\section{$\underline{\text { Archival sources }}$}

Bodleian Library, Oxford

MSS. Brit. Emp. s. 22 / G360

Papers of the Anti-Slavery Society: Cocos Islands (1937-1941) 
National Archives of Australia

A6180

Visit of the Minister for Home Affairs to the Cocos Islands, 1982

A9752 / 115 Invoices from Caldbeck MacGregor to J. S. Clunies Ross

A9752 / 116 Accounts and correspondence, Caldbeck MacGregor and Company with J S Clunies Ross (1921-1933)

A9752 / 119 Caldbeck MacGregor - Accounts and indents and correspondence

A9752 / 138 Supplies Required (1946-1947)

A9752 / R Photographs taken by Mrs J C Clunies Ross on Cocos

National Archives of the United Kingdom

ADM 125/131 The Cocos or Keeling Islands and Seychelles (1830-1839)

CO 537/3656 Cocos Islands: Emergency Organisations (contains 'M. J. Ross, Report on a visit to Cocos and Christmas Islands', 6 May 1948)

$\operatorname{CO} 273 / 673 / 9$ Cocos Islands: Emergency Organisation (contains 'Report for the month of May 1945', 6 June 1945)

Royal Botanic Gardens Library and Archives $\mathrm{HNR} / 5 / 15$ Henry Nicholas Ridley, 'Visits to Cocos and Christmas Islands', Ms., n.d.

\section{Published sources}

Abbott, R. Tucker. 1950. 'The Molluscan Fauna of the Cocos-Keeling Islands, Indian Ocean'. Bulletin of the Raffles Museum 22: 68-98.

Ackrill, Margaret. 1984. 'The Origins and Nature of the First Permanent Settlement on the Cocos-Keeling Islands'. Historical Studies 21, no. 83: 229-44.Australian Government. 2018. Cocos (Keeling) Islands Act 1955. Canberra: AttorneyGeneral's Department.

Bachmann, Werner. 1969. The Origins of Bowing and the Development of Bowed Instruments up to the Thirteenth Century. Translated by Norma Deane. London: Oxford University Press.

Bates, Eliot. 2012. 'The Social Life of Musical Instruments'. Ethnomusicology 56(3):36395. 
Birch, Ernest Woodford. 1885. The Report of Mr. E.W. Birch, Deputed by the Officer Administering the Government of the Straits Settlements (Mr. Cecil C. Smith, C.M.G.) to Visit the Cocos-Keeling Islands. [Singapore]: n.pub.

British Movietone. 1954. 'Royal Tour. Queen at Cocos Islands and Ceylon' (22 April 1954).

http://www.aparchive.com/metadata/youtube/ab97b21b8f8c4f35a81cd7b2a2 3e83ed (accessed 3 April 2020).

British Pathé. 1954. 'Queen in Coco's Isles [sic]'. https://www.britishpathe.com/video/queen-in-cocos-isles/ (accessed 3 April 2020).

Brockman, Rosemary Ann. 1981. 'Captives on Cocos: The Origins and Evolution of the Plantation Community of the Cocos (Keeling) Islands'. MPhil thesis, Murdoch University, Perth.

Budasz, Rogério. 2001. 'The Five-Course Guitar (Viola) in Portugal and Brazil in the Late Seventeenth and Early Eighteenth Centuries'. PhD dissertation, University of Southern California.

Bunce, Pauline. 1988. The Cocos (Keeling) Islands: Australian Atolls in the Indian Ocean. Milton, QLD: Jacaranda.

_- - 2012. 'Out of Sight, out of Mind... And out of Line. Language Education in the Australian Indian Ocean Territory of the Cocos (Keeling) Islands'. In English Language as Hydra: Its Impacts on Non-English Language Cultures, edited by Vaughan Rapatahana and Pauline Bunce, 37-59. Bristol, Buffalo and Toronto: Multilingual Matters.

Clunies-Ross, John C., compiler. 2009. The Clunies-Ross Chronicle. [Perth]: John C. Clunies-Ross.

Cocos-Keeling and Christmas Islands: Report on the Annual Visit for 1897. 1897.Colonial Reports-Annual. No. 216. London: Printed for His Majesty's Stationery Office, by Darling \& Son, Ltd. 
Cocos-Keeling and Christmas Islands. Report on the Annual Visit for 1898. 1899. Colonial Reports-Annual. No. 257. London: Printed for His Majesty's Stationery Office, by Darling \& Son, Ltd.

Cohen, Matthew Isaac. 2006. Komedie Stamboel: Popular Theater in Colonial Indonesia, 1891-1903. Athens, Ohio: Ohio University Press.

Darwin, Charles. 1839. Journal and Remarks. 1832-1836. Narrative of the Surveying Voyages of His Majesty's Ships Adventure and Beagle: Between the Years 1826 and 1836. Vol. 3, London: H. Colburn.

Dawe, Kevin, ed. 2004. Island Musics. Oxford and New York: Berg.

Dawe, Kevin. 2012. 'The Cultural Study of Musical Instruments'. In The Cultural Studyof Music: A Critical Introduction, 2nd edition, edited by Martin Clayton, Trevor Herbert and Richard Middleton, 195-205. New York and London: Routledge.

Deshayes, G.P. 1839. 'Nouvelles espèces de mollusques, provenant des côtes de la Californie, du Mexique, du Kamtschatka et de la Nouvelle-Zélande'. Revue Zoologique par la Société Cuvierienne 2 (12): 356-361.

Doubleday, Veronica. 2008. 'Sounds of Power: An Overview of Musical Instruments and Gender'. Ethnomusicology Forum 17 (1): 3-39.

Dutt, Srikant. 1981. 'The Cocos-Keeling Islands'. Journal of Southeast Asian Studies 12(2): 476-83.

Fellezs, Kevin. 2019. Listen But Don't Ask Question: Hawaiian Slack Key Guitar Across the Transpacific. Durham: Duke University Press.

Fétis, François-Joseph. 1856. Antoine Stradivari, luthier célèbre connu sous le nom de Stradivarius: précédé de recherches historiques et critiques sur l'origine et les transformations des instruments à archet et suivi d'analyses théoriques sur l'archet et sur François Tourte, auteur de ses derniers perfectionnements. Paris: Vuillaume.

Gibson-Hill, Carl Alexander. 1946. 'Boats and Fishing on the Cocos-Keeling Islands'. The Journal of the Royal Anthropological Institute of Great Britain and Ireland 76(1): 13-23.

_- - 1947. "Notes on the Cocos-Keeling Islands". Journal of the Malayan Branch ofthe Royal Asiatic Society 20(2): 140-202. 
_- - 1952. 'Documents Relating to John Clunies Ross, Alexander Hare and the Early History of the Settlement on the Keeling Islands'. Journal of the Malayan Branch of the Royal Asiatic Society 25(4): 5-306.

Gullick, John M. 1987. Malay Society in the Late Nineteenth Century: The Beginnings of Change. Singapore: Oxford University Press.

Herriman, Nicholas. 2014. Naming and Binding. Cocos (Keeling) Islands Fieldwork. Accessed 5 September 2019.

<http://nicholasherriman.blogspot.com/2014/02/naming-and-family.html>.

Herriman, Nicholas, David R. M. Irving, Greg Acciaioli, Monika Winarnita, and Trixie Tangit Kinajil. 2018. 'A Group of Southeast Asian Descendants Wants to Be Recognised as Indigenous Australians'. The Conversation. Published electronically 25 June 2018. <https://theconversation.com/a-group-ofsoutheast-asian-descendants-wants-to-be-recognised-as-indigenous-australians98186>. Accessed 29 February 2020.

Hobson, Valerie. 2008. Our Island Home: The Story of the Circumstances Which Led to the Cocos Malays Relocating to Western Australia - Some Via Christmas Island. Sydney: Frontier Services.

Hughes, John Scott. 1950. Kings of the Cocos: The Story of the Settlement on the Atoll of Keeling-Cocos in the Indian Ocean: Composed Mainly from Contemporary Accounts. London: Methuen.

Hunt, John G. 1989. 'The Revenge of the Bantamese: Factors for Change in the Cocos (Keeling) Islands, 1930-1978'. MA thesis. Australian National University, Canberra.

Irving, David R. M. 2010. Colonial Counterpoint: Music in Early Modern Manila. New York: Oxford University Press.

—_- 2014. 'Hybridity and Harmony: Nineteenth-century British Discourse on Syncretism and Intercultural Compatibility in Malay Music'. Indonesia and the Malay World 42 (123): 197-221.

- - - Forthcoming. 'Transplanted Musics in a Plantation Society: Performing Arts on the Cocos (Keeling) Islands, 1826-1955'. 
Irving, David R. M., and Jenny McCallum. Forthcoming. 'The World of Cocos Malay Music and Dance: A Documentary Film on Performing Arts in the Cocos (Keeling) Islands'.

Kamaruddin, Noorazean, and Arba'iyah Ab Aziz. 2018. 'The Entities of Cocos Malays [sic] Communities in Sabah'. In Proceedings of the Art and Design International Conference (ANDIC 2016), edited by Rusmadiah Anwar, Muliyadi Mahamood, D'zul Haimi Md. Zain, Mohamad Kamal Abd Aziz, Oskar Hasdinor Hassan and Shahriman Zainal Abidin, 355-64. Singapore: Springer.

Kartomi, Margaret. 2012. Musical Journeys in Sumatra. Urbana, Ill.: University of Illinois Press.

Laufman, Dudley, and Jacqueline Laufman. 2009. Traditional Barn Dances with Calls \& Fiddling. Vol. 1. Champaign, Ill.: Human Kinetics.

Linford, Pat. 1994. The Coconut Revolution: A Personal Account. Red Hill, ACT: P.Linford. Linford, Robert J. [2009]. Indian Ocean Atoll: A History of the Cocos (Keeling) Islands. Narrabundah, ACT: Patricia P. Linford.

Maes, Virginia Orr. 1967. “The Littoral Marine Mollusks of Cocos-Keeling Islands(Indian Ocean)." Proceedings of the Academy of Natural Sciences of Philadelphia 119:93217.

Marsden, William. 1783. The History of Sumatra: Containing an Account of the Government, Laws, Customs, and Manners of the Native Inhabitants, with a Description of the Natural Productions, and a Relation of the Ancient Political State of That Island. London: printed for the author, and sold by Thomas Payne and Son, Mew's-Gate; Benjamin White, Fleet-street; James Robson, New Bond-street; P. Elmsly, Strand; Leigh and Sotheby, York-street Covent Garden; and J. Sewell, Cornhill.

Matusky, Patricia, and Tan Sooi Beng. 2004. The Music of Malaysia: The Classical, Folk and Syncretic Traditions. Aldershot: Ashgate.

McCallum, Jenny. Forthcoming-a. 'Being Distinctive: Cocos Malay Islamic Music in the Cocos (Keeling) Islands, Mainland Australia and Beyond'.

——_. Forthcoming-b. “'We Don't Eat Turtle Any More”: Perspectives on Music Endangerment and Sustainability from the Cocos (Keeling) Islands'.

Minister for Infrastructure and Regional Development (Australian Government), 'IOT Community Development Grants Programme Delivered', Media Release 
JB050/2014, 6 June 2014, Internet:

<http://minister.infrastructure.gov.au/jb/releases/2014/June/jb050_2014.aspx

$>$ (accessed 2 July 2018).

Montagu, Jeremy. 2007. Origins and Development of Musical Instruments. Lanham:

Scarecrow Press.

Mowbray, Martin. 1997. 'The Cocos (Keeling) Islands: A Study in Political and Social

Change'. Australian Journal of International Affairs 51(3): 383-97.

Papers Relating to the Cocos-Keeling and Christmas Islands. 1897. London: Printed for

Her Majesty's Stationery Office, by Eyre and Spottiswoode.

'Projects Funded under IOT Community Development Grants Programme Round One'.

Internet: <http://regional.gov.au/territories/indian_ocean/files/OIT-DGP-

Round1.pdf>. Accessed 2 July 2018.

'Queen to Meet a Brown Mr. McTavish'. 1954. The Mail (Adelaide) (3 April): 51.

Rabuhu Anthony. 2003. 'Cocos (Keeling) Islands Traditions'. In Currency Companion to

Music \& Dance in Australia, edited by John Whiteoak and Aline Scott-Maxwell, 150. Sydney: Currency House in association with Currency Press.

Scarfe, Brigitta, and Muhamad Hasbi. 2019. 'The Significance of Place in the Musical

Practice of Two Biola Players in Riau Islands Province'. In Performing the Arts of Indonesia: Malay Identity and Politics in the Music, Dance and Theatre of the Riau Islands, edited by Margaret Kartomi, 152-68. Copenhagen: NIAS Press.

Schippers, Huib, and Catherine Grant. 2016. 'Sustainable Futures for Music Cultures: An Ecological Perspective'. In Sustainable Futures for Music Cultures: An Ecological Perspective, edited by Huib Schippers and Catherine Grant, 333-51. New York: Oxford University Press.

Slocum, Joshua. 1900. Sailing Alone around the World. New York: Century.

Swift, Gordon N. 1990. 'South Indian Gamaka and the Violin'. Asian Music 21 (2):71-89. Tahmindjis, Phillip. 1985. 'Australia, the Cocos Islands and Self-Determination'. Queensland Institute of Technology Law Journal 1(1): 177-198.

Tarling, Nicholas. 1959. 'The Annexation of the Cocos-Keeling Islands'. Historical Studies: Australia and New Zealand 8(32): 400-04.

Toynbee, Jason, and Byron Dueck. 2011. 'Migrating Music'. In Migrating Music, edited by Jason Toynbee and Byron Dueck, 1-17. London and New York: Routledge. 
United Nations Department of Political Affairs, Trusteeship and Decolonization. 1978. Decolonization 11. Issue on Cocos (Keeling) Islands. Internet: <https://www.un.org/en/decolonization/pdf/decolonization/decon_num_11.pd f>. Accessed 12 February 2014.

United Nations Involvement with Australia's Territories: Report from the Senate Standing Committee on Foreign Affairs and Defence. 1975. Canberra: Australian Government Publishing Service.

Weidman, Amanda J. 2006. Singing the Classical, Voicing the Modern: The Postcolonial Politics of Music in South India. Durham, NC, and London: Duke University Press.

Weintraub, Andrew. 2010. 'Music and Malayness: Orkes Melayu in Indonesia, 19501965'. Archipel 79: 57-78.

Welsh, Alistair. 2015. 'Cocos Malay Language since Integration with Australia'. Shima: The International Journal of Research into Island Cultures 9(1): 53-68.

Winarnita, Monika, and Nicholas Herriman. 2012. 'Caring and Family: Marriage Migration to the Malay Muslim Community of Home Island (Cocos Keeling Islands)'. Indonesia and the Malay World 40(118): 372-87.

Wood-Jones, Frederic. 1912. Corals and Atolls: A History and Description of the KeelingCocos Islands, with an Account of Their Fauna and Flora, and a Discussion of the Method of Development and Transformation of Coral Structures in General. Reissue [with new prefatory matter]. London: Reeve. 


\section{Strings Across the Ocean: Practices, Traditions, and Histories of the Cocos Malay Biola in the Cocos (Keeling) Islands, Indian Ocean}

\section{Captions for maps, figures, and musical examples, with formatting}

Cover image: Nek Yusri (Zainal bin Wallie) playing biola and Nek Tiara (Woren bin Dedian) playing gendang for a bangsawan performance on Home Island, the Cocos (Keeling) Islands, Indian Ocean. Photograph by Jenny McCallum, 16 July 2016

Map 1. Location of the Cocos (Keeling) Islands in the Indian Ocean. Map by author Map 2. The Cocos (Keeling) Island atoll. Map by Joanne Byrne. Used by permission Figure 1: Nek Yusri (Zainal bin Wallie) playing biola and Nek Tiara (Woren bin Dedian) playing gendang for a bangsawan performance on Home Island, Cocos. Photograph by Jenny McCallum, 16 July 2016

Figure 2: Standard manner of holding the bow in Cocos biola technique, demonstrated by Nek Yusri (Zainal bin Wallie), as seen from below. Photograph by author, 2016

Figure 3: New acoustic and electric violins on Cocos. Photograph by author, 2015

Figure 4: Nek Yusri (Zainal bin Wallie) playing the new electric violin and Nek Tiara (Woren bin Dedian) playing gendang, to accompany a performance of the melenggok dance by Nek Su (Ramnie bin Mokta) and Nek Shafiq, for celebrations following Hari Raya in 2016. Photograph by Jenny McCallum, 2016

Figure 5: Nek Sumilla (Dennis bin Mokta) practising the biola. Photograph by author, 2015

Figure 6: Kepala biola shells collected by the shoreline on Home Island, Cocos. Photograph by author, 2015

Figure 7: Kepala biola cooked as a stew. Photograph by author, 2015

Figure 8: Biola being played in a procession accompanying Queen Elizabeth II, 1954. Still no. 382 from <https://www.britishpathe.com/video/stills/queen-in-cocos-isles>. Reproduced by permission of British Pathé

Figure 9: Biola being played in entertainments for Queen Elizabeth II, 1954. Still no. 429 from <https://www.britishpathe.com/video/stills/queen-in-cocos-isles $>$. Reproduced by permission of British Pathé 
Figure 10: Nek Bail (Alpan bin Puria) and Nek Yusri (Zainal bin Wallie) playing biola in the Club Lama (old club building). 'Photographs taken by Mrs J C Clunies Ross on Cocos' (dated 1940-1949 but probably from the 1960s). Image courtesy of the National Archives of Australia. NAA: A9752 R, 58.

Figure 11: Australian Minister for Home Affairs, Tom McVeigh, touches the scroll of the biola belonging to Nek Yusri (Zainal bin Wallie), with Nek Mazlan (Colin bin Puria) in the background. 'Visit of the Minister for Home Affairs to the Cocos Islands, 1982'. Image courtesy of the National Archives of Australia. NAA: A6180, 8/12/82/31

Musical Example 1. Descriptive transcription by author of dansa tune 'Burung hitam nyambar di telok' (Black bird lands on a lake), played by Nek Yusri (Zainal bin Wallie), 13 July 2016

Musical Example 2. Descriptive transcription by author of melenggok melody 'Dendang Melaka', played by Nek Yusri (Zainal bin Wallie), 13 July 2016 
i

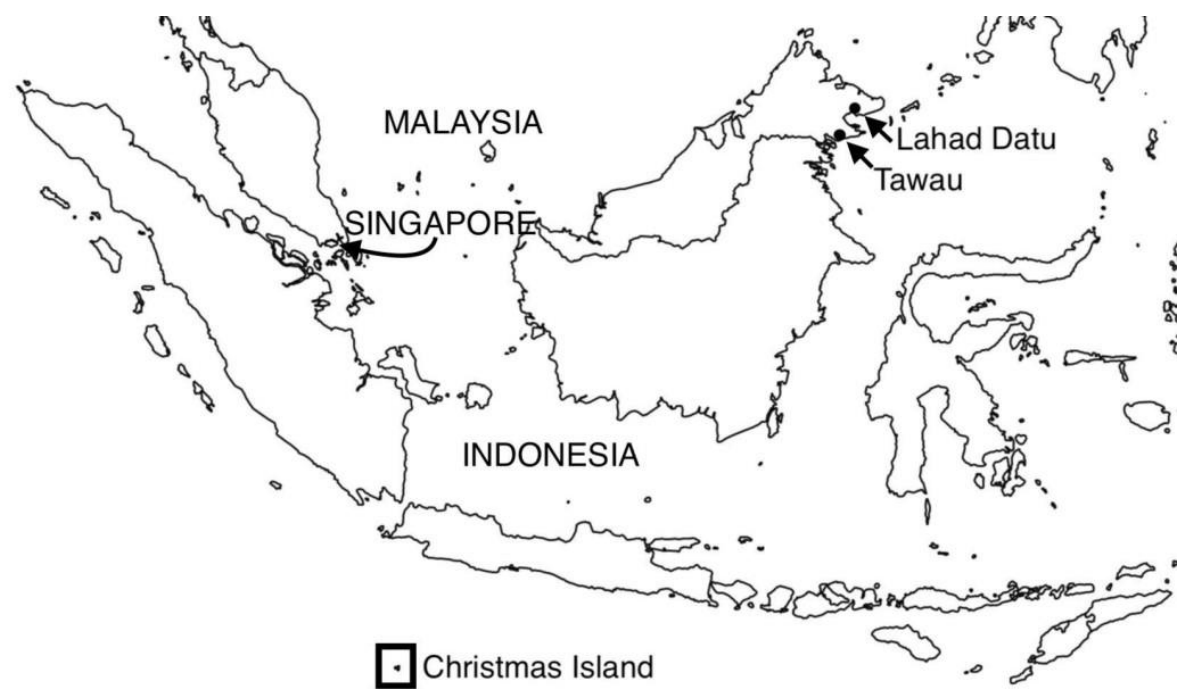

$\square$ Cocos (Keeling) Islands

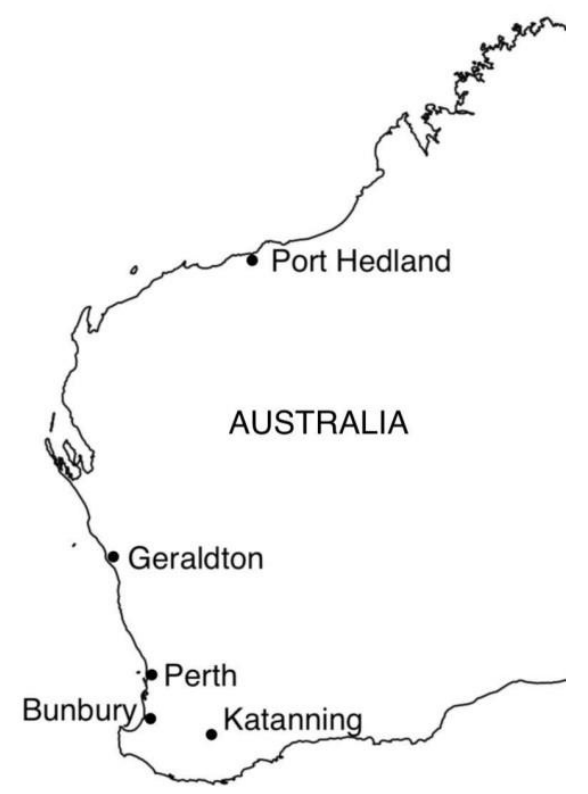

Map 1. Location of the Cocos (Keeling) Islands in the Indian Ocean. Map by author 


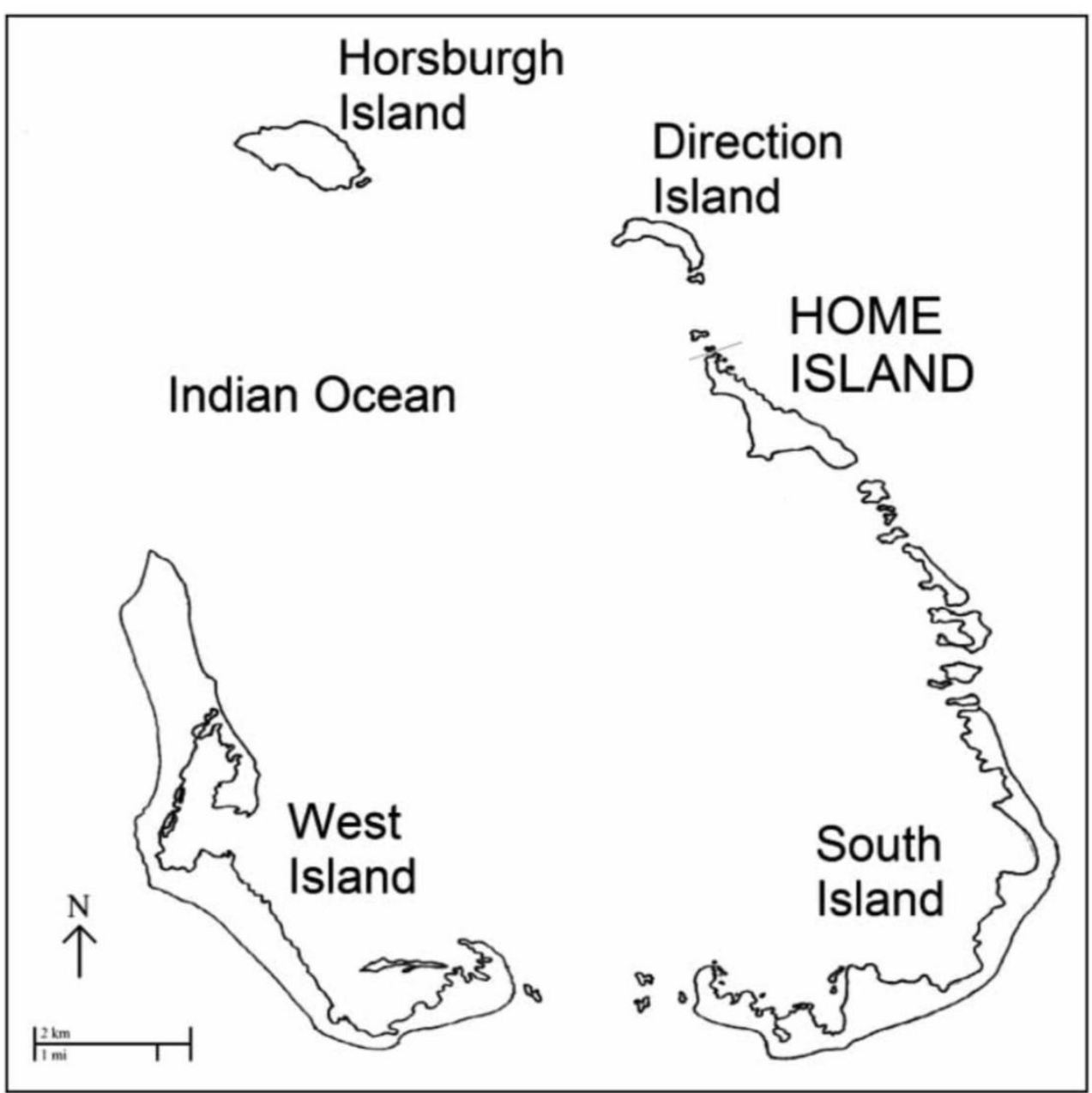

Map 2. The Cocos (Keeling) Island atoll. Map by Joanne Byrne. Used by permission $223 \times 222 \mathrm{~mm}(144 \times 144 \mathrm{DPI})$ 


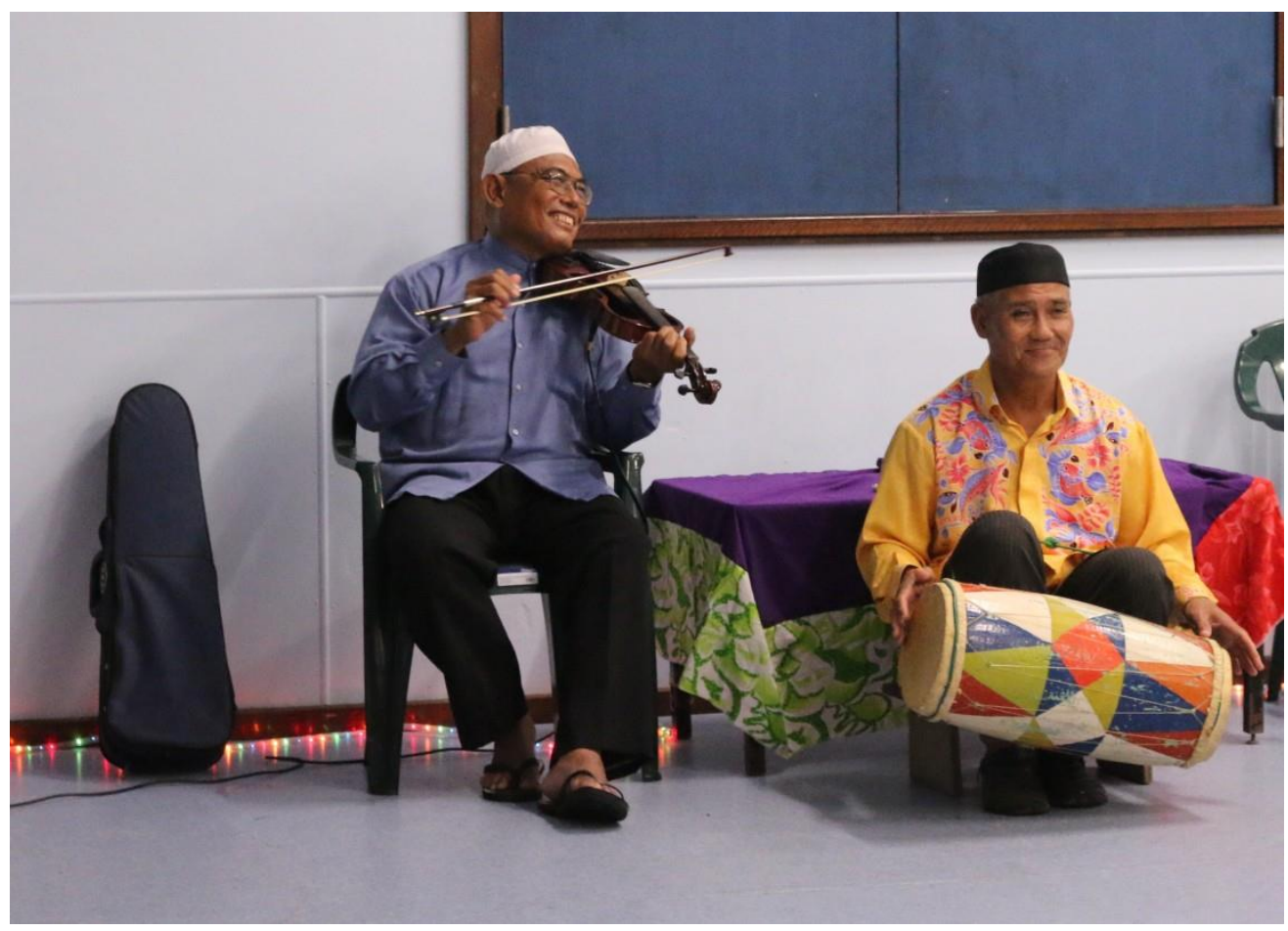

Figure 1: Nek Yusri (Zainal bin Wallie) playing biola and Nek Tiara (Woren bin Dedian) playing gendang fora bangsawan performance on Home Island, Cocos. Photograph by Jenny McCallum, 16 July 2016 $1220 \times 874 \mathrm{~mm}(72 \times 72 \mathrm{DPI})$ 


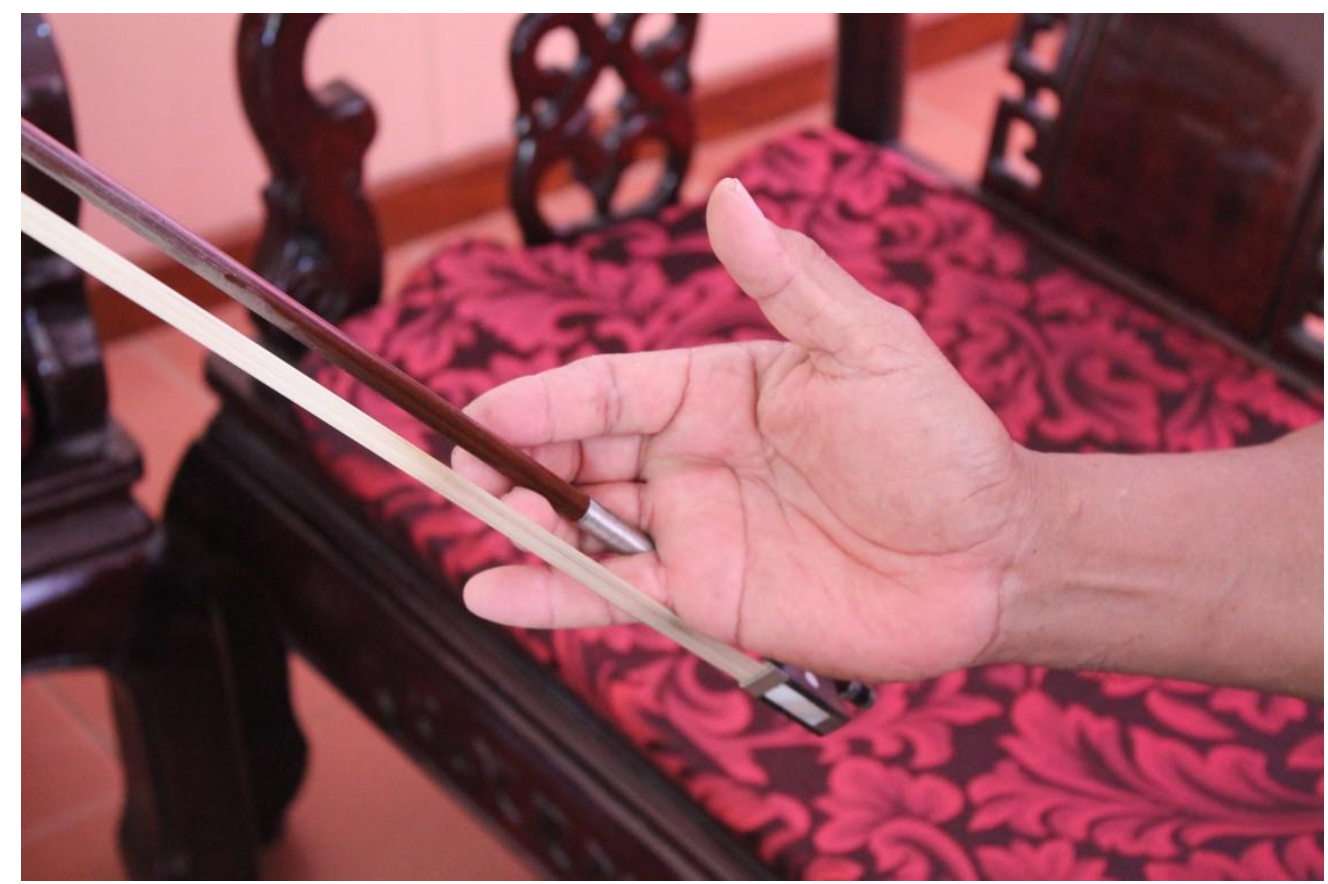

Figure 2: Standard manner of holding the bow in Cocos biola technique, demonstrated by Nek Yusri (Zainal bin Wallie), as seen from below. Photograph by author, 2016 


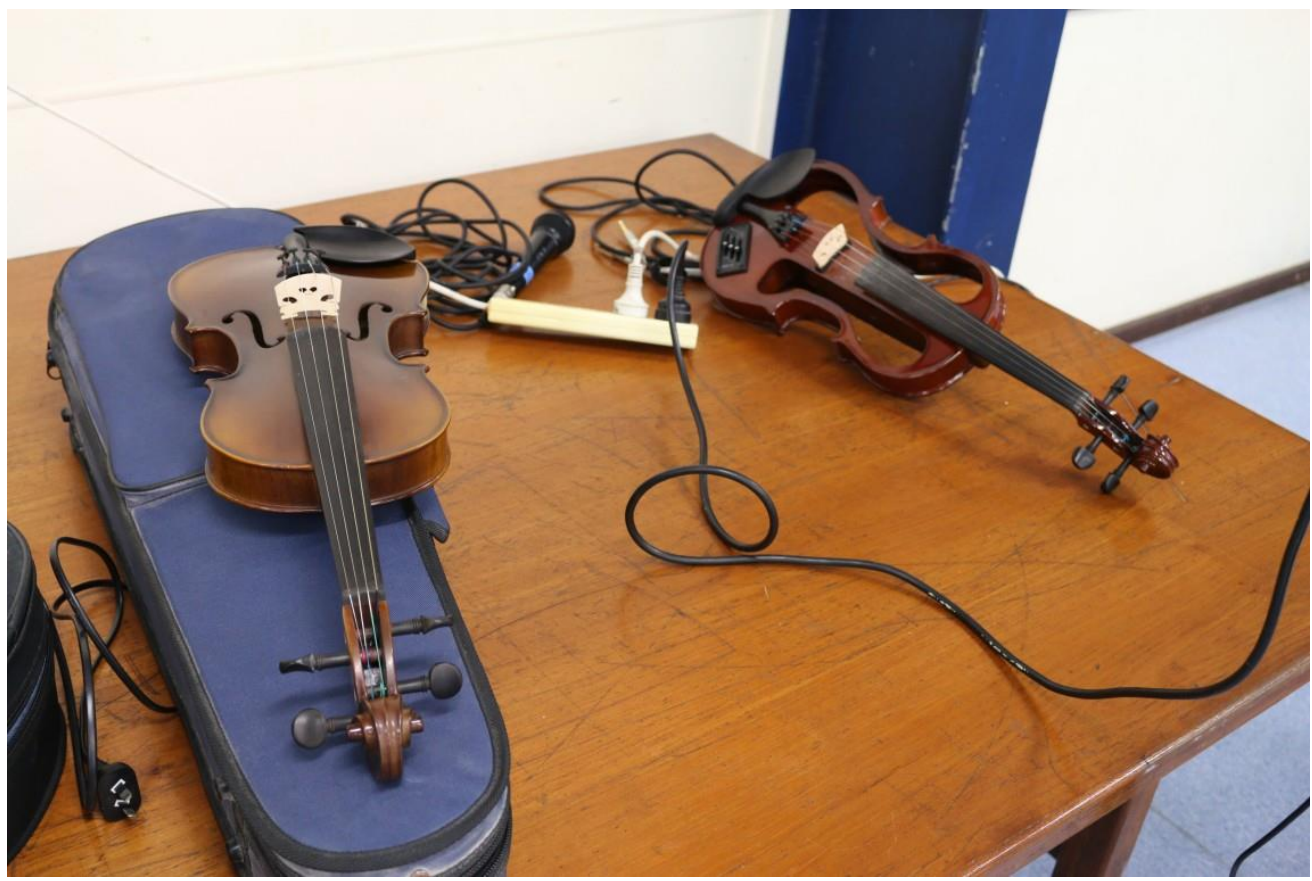

Figure 3: New acoustic and electric violins on Cocos. Photograph by author, 2015 $1286 \times 857 \mathrm{~mm}(72 \times 72 \mathrm{DPI})$ 


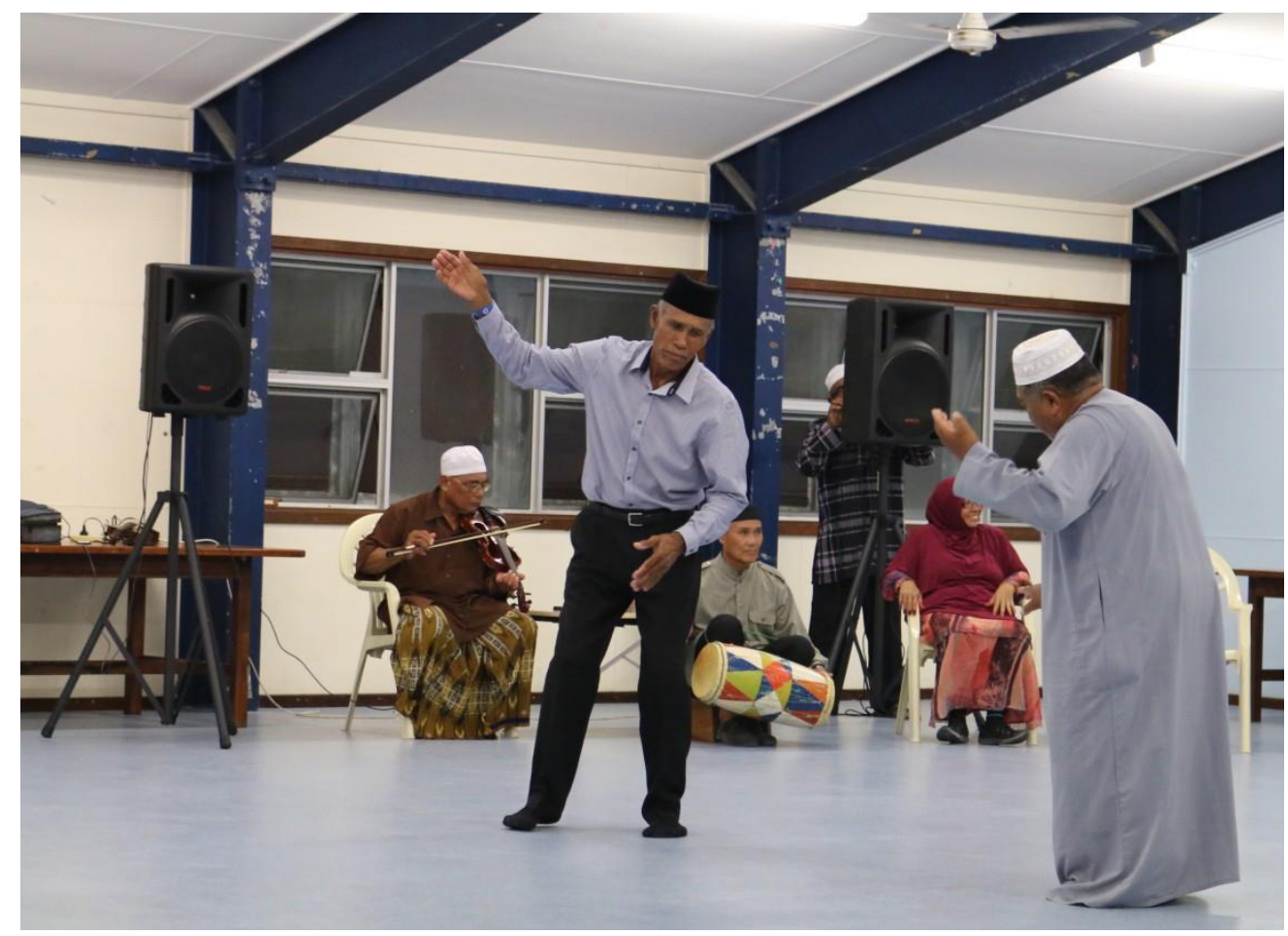

Figure 4: Nek Yusri (Zainal bin Wallie) playing the new electric violin and Nek Tiara (Woren bin Dedian) playing gendang, to accompany a performance of the melenggok dance by Nek Su (Ramnie bin Mokta) and Nek Shafiq, for celebrations following Hari Raya in 2016. Photograph by Jenny McCallum, 2016

$$
1017 \times 739 \mathrm{~mm}(72 \times 72 \text { DPI })
$$




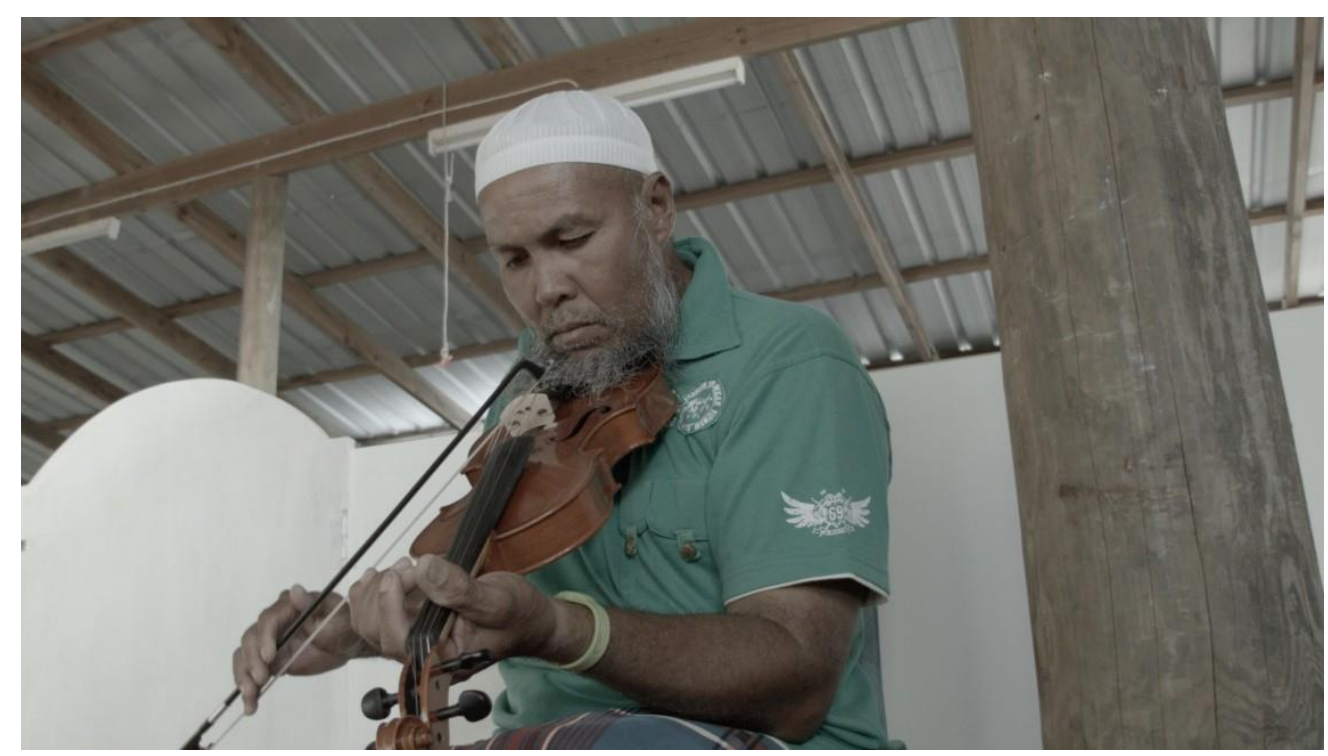

Figure 5: Nek Sumilla (Dennis bin Mokta) practising the biola. Photograph by author, 2015 $677 \times 381 \mathrm{~mm}(72 \times 72 \mathrm{DPI})$ 


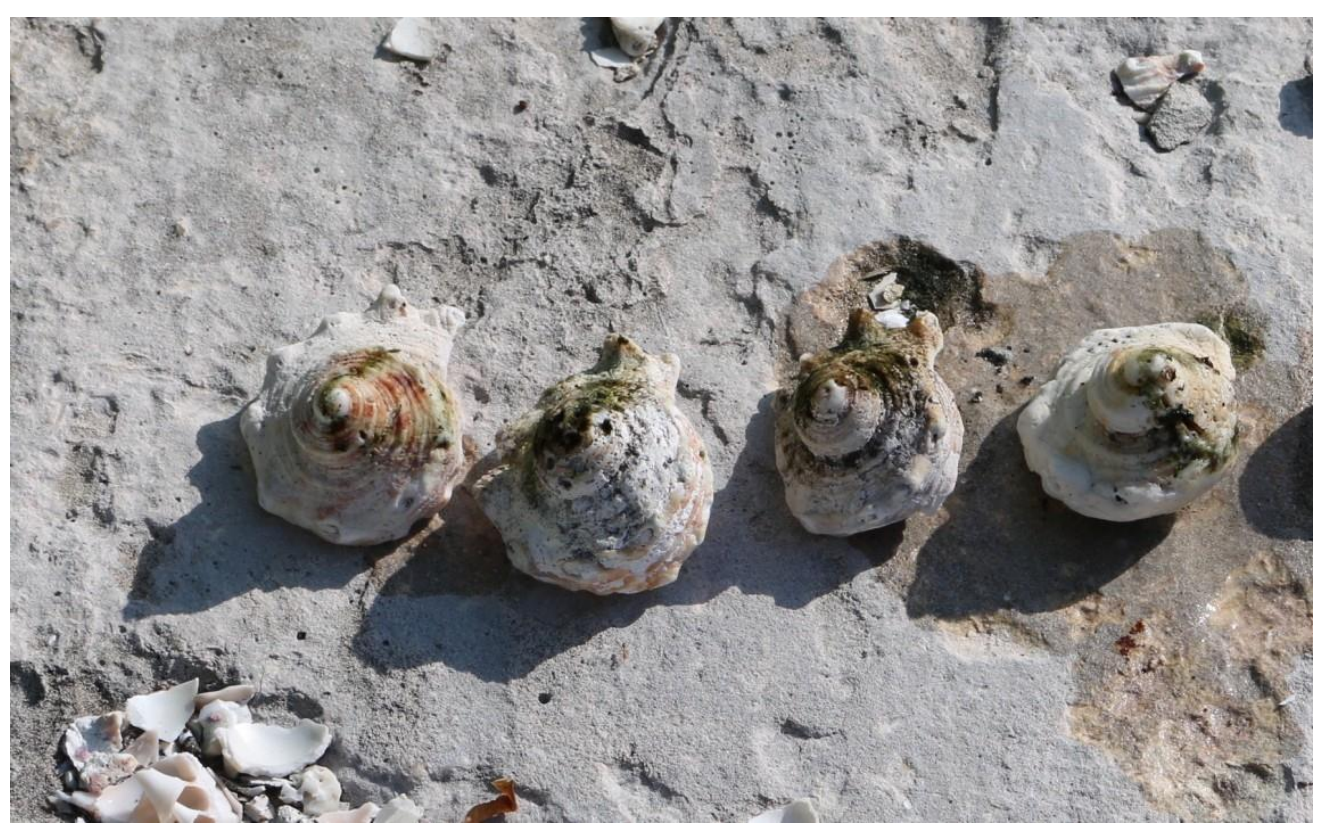

Figure 6: Kepala biola shells collected by the shoreline on Home Island, Cocos. Photograph by author, 2015 $626 \times 387 \mathrm{~mm}(72 \times 72 \mathrm{DPI})$ 


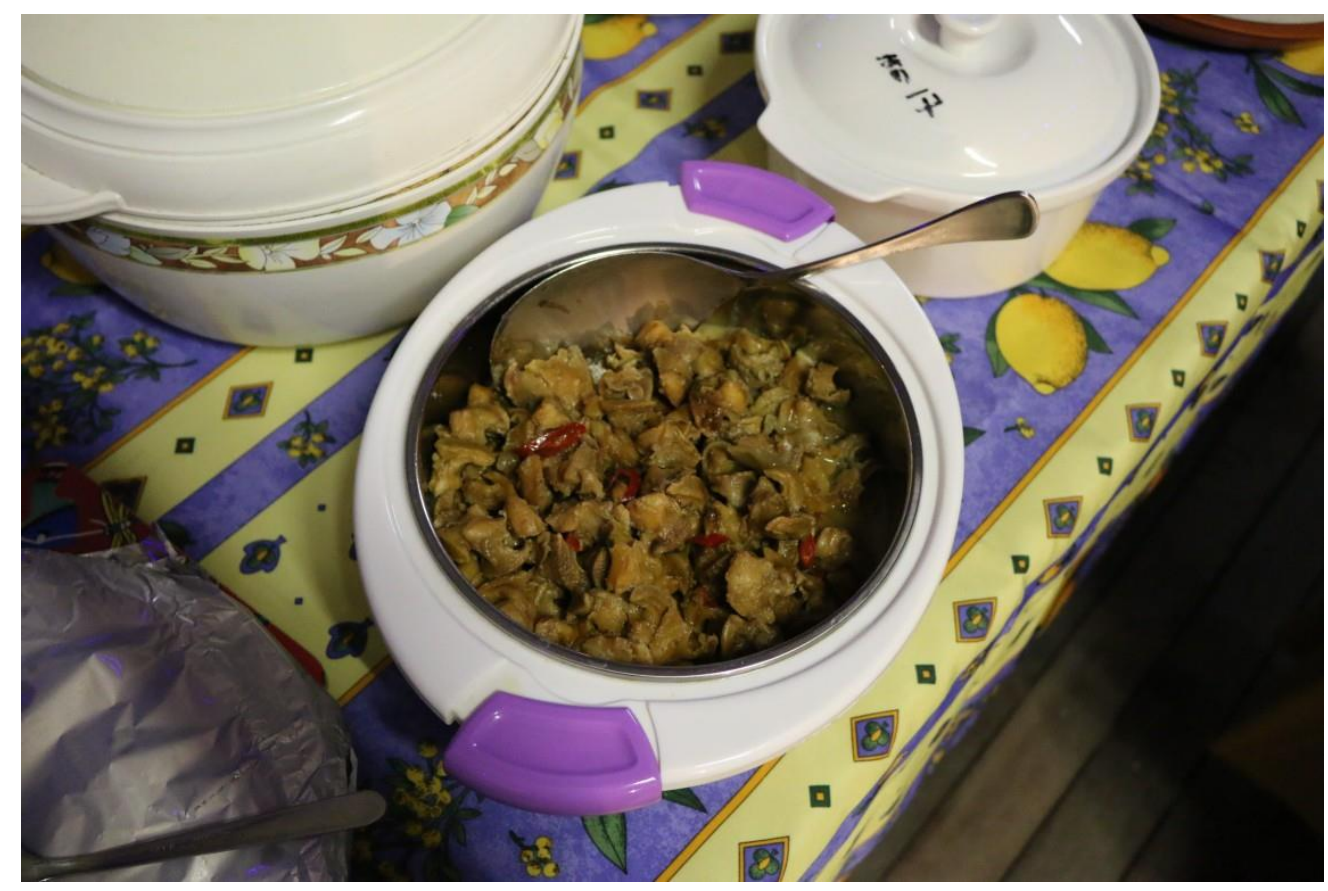

Figure 7: Kepala biola cooked as a stew. Photograph by author, 2015 $1286 \times 857 \mathrm{~mm}(72 \times 72 \mathrm{DPI})$ 


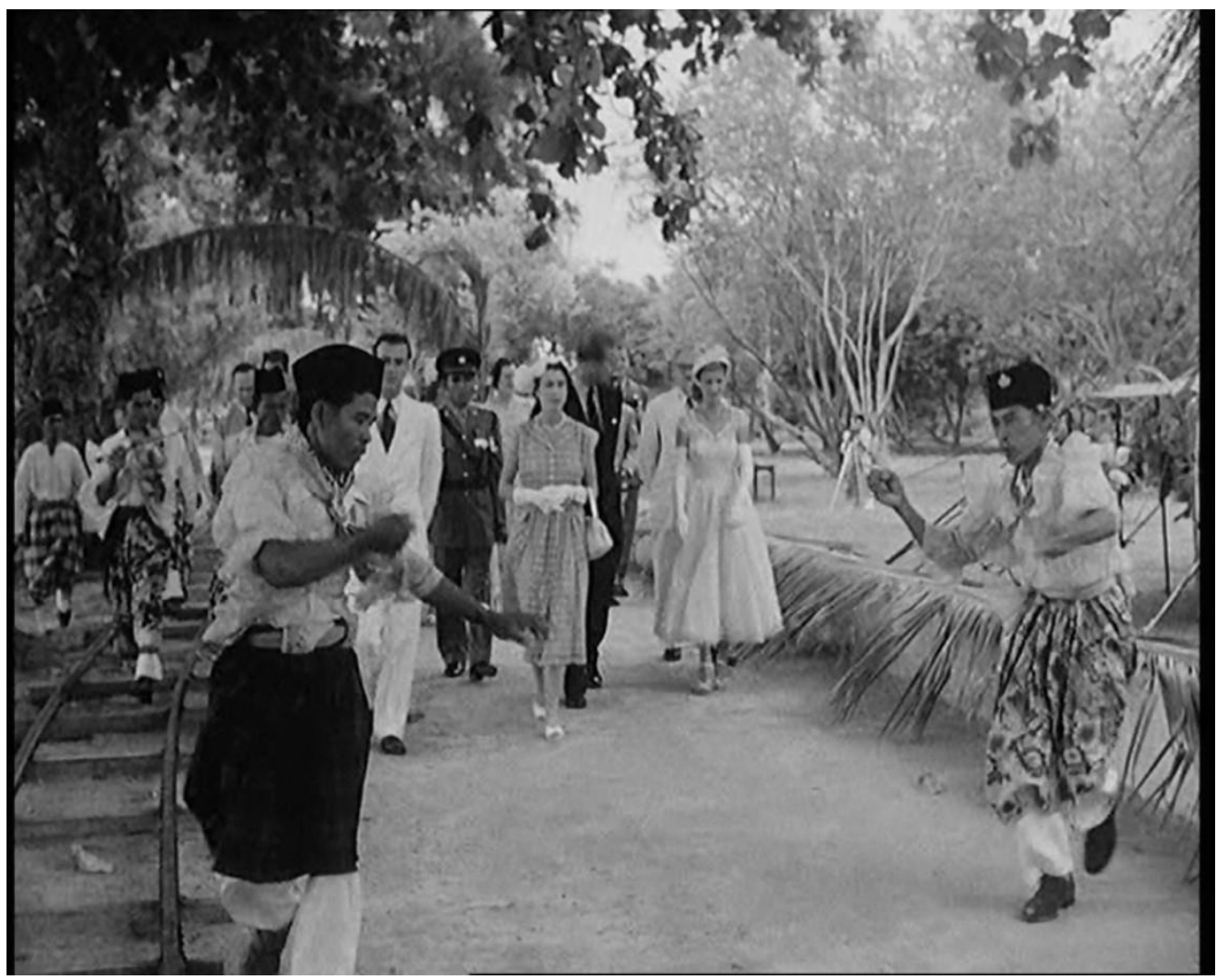

Figure 8: Biola being played in a procession accompanying Queen Elizabeth II, 1954. Still no. 382 from <https://www.britishpathe.com/video/stills/queen-in-cocos-isles>. Reproduced by permission of British Pathé

$121 \times 97 \mathrm{~mm}(300 \times 300 \mathrm{DPI})$ 


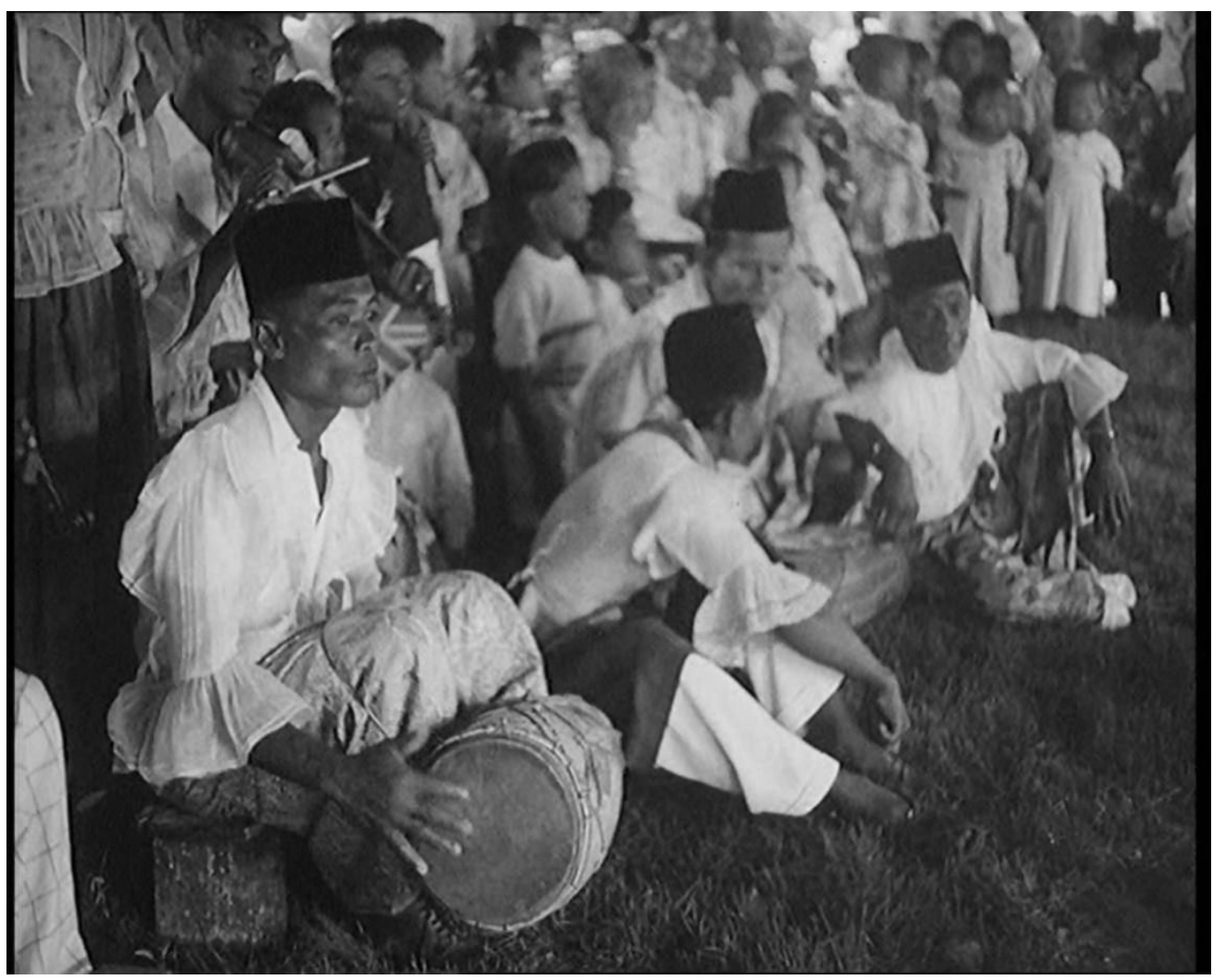

Figure 9: Biola being played in entertainments for Queen Elizabeth II, 1954. Still no. 429 from <https://www.britishpathe.com/video/stills/queen-in-cocos-isles>. Reproduced by permission of British Pathé

$121 \times 97 \mathrm{~mm}(300 \times 300 \mathrm{DPI})$ 


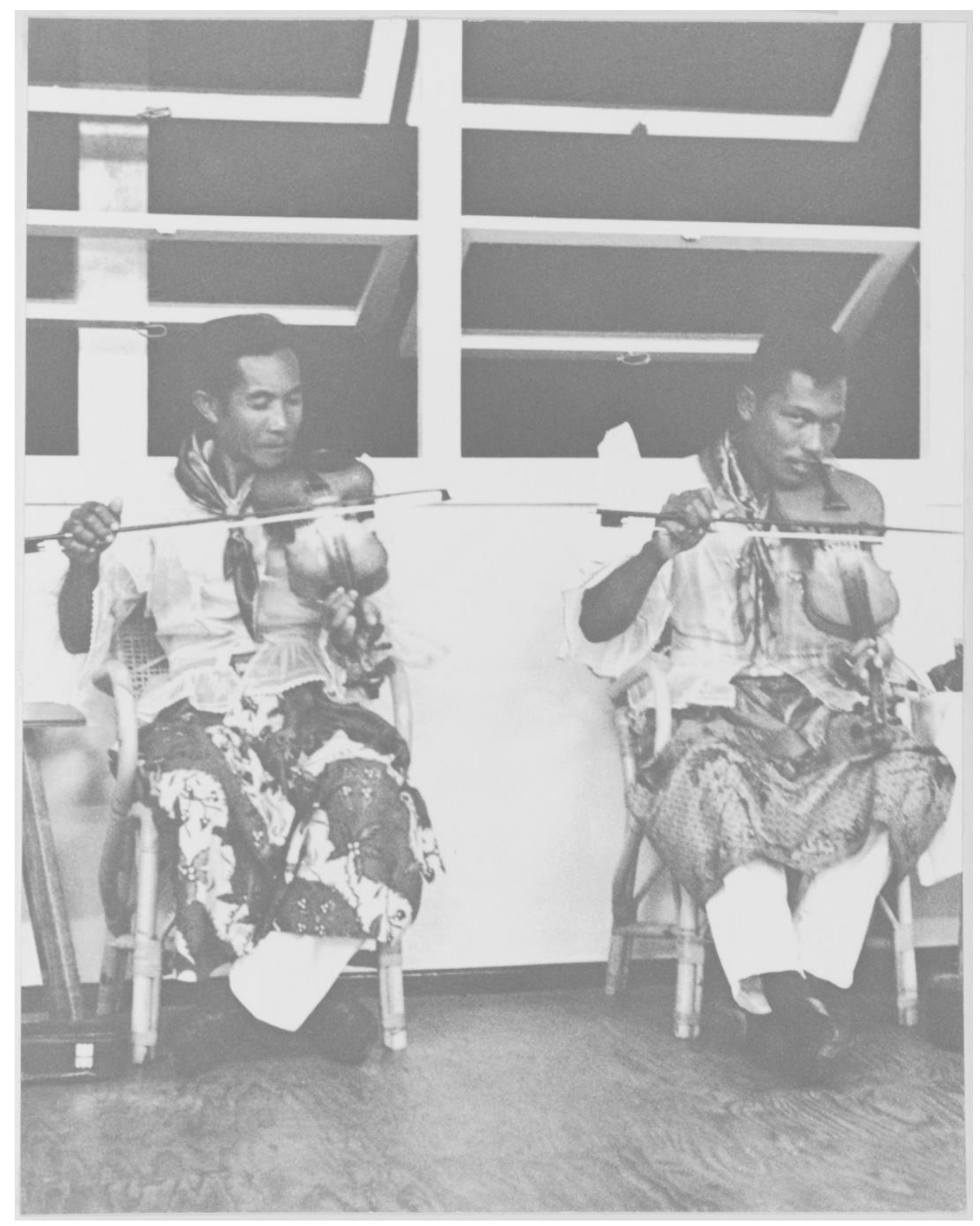

Figure 10: Alpan bin Puria and Zainal bin Wally playing biola in the Club Lama (old club building). 'Photographs taken by Mrs J C Clunies Ross on Cocos' (dated 1940-1949 but probably from the 1960s). Image courtesy of the National Archives of Australia. NAA: A9752 R, 58. 


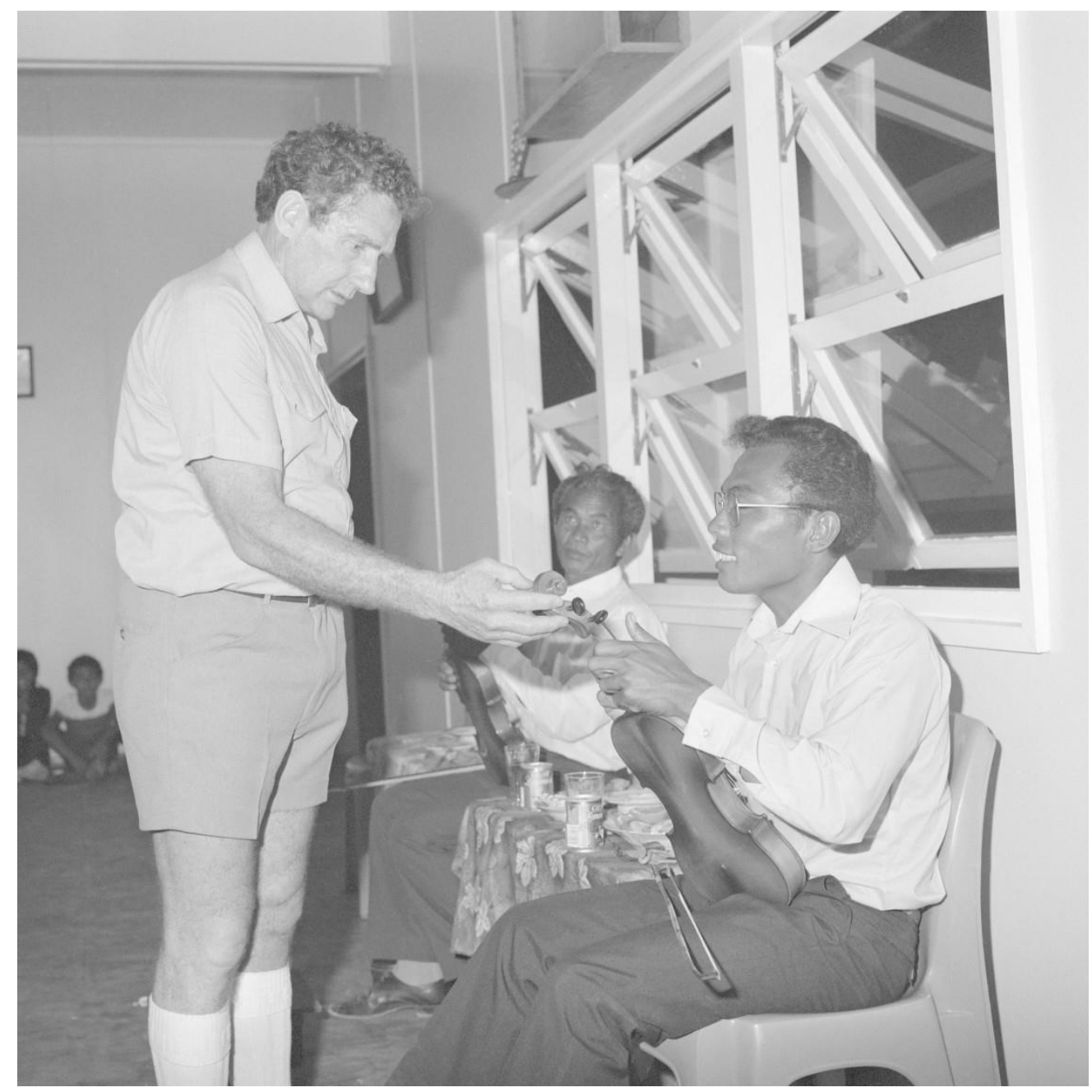

Figure 11: Australian Minister for Home Affairs, Tom McVeigh, touches the scroll of the biola belonging to Nek Yusri (Zainal bin Wallie), with Nek Mazlan (Colin bin Puria) in the background. 'Visit of the Minister for Home Affairs to the Cocos Islands, 1982'. Image courtesy of the National Archives of Australia. NAA: A6180, $8 / 12 / 82 / 31$ 
Table 1: Nek Yusri (Zainal bin Wallie), repertoire of biola melodies recorded by Jenny McCallum on 29 July 2016

1. Dendang Melaka [Melakadendang]

2. Selerang Hitam Manis [sweet blackscarf]

3. Selerang kecik [smallscarf]

4. Selerang besar [bigscarf]

5. Centek Manis Gunung [Beautiful mountain]

6. Dendang Tanah Merah [Tanah Merah dendang (Tanah Merah is a place name in Singapore and elsewhere; it literally means 'red earth']

7. Dendang kemantin [weddingdendang]

8. Wak Ketok [a dance named after a person]

9. Labuan tidak berbukit [No hills in Labuan]

10. Sayang seribu sayang [A thousand loves]

11. Burung bayan patah kakinya [Parakeet with a broken leg]

12. Burung hitam nyambar di teluk [Black bird lands on the lake]

13.Pulu Luar [the name of a local island, literally 'exterior island'; known in English as Horsburgh Island]

14. Nek Nija [dance named after a person, in this case a grandparent of a child named Nija]

15. Commander Davis [dance named after a person]

16. Dansa Cocos [a traditional genre of Cocos Malay dance]

17. Mrs Rae [dance named after a person]

18. Dansa orang delapan [Dance of eight people] 
Musical Example 1. Dansa tune, 'Burung hitam nyambar di telok' (Black bird lands on a lake), performed by Nek Yusrie, 13 July 2016
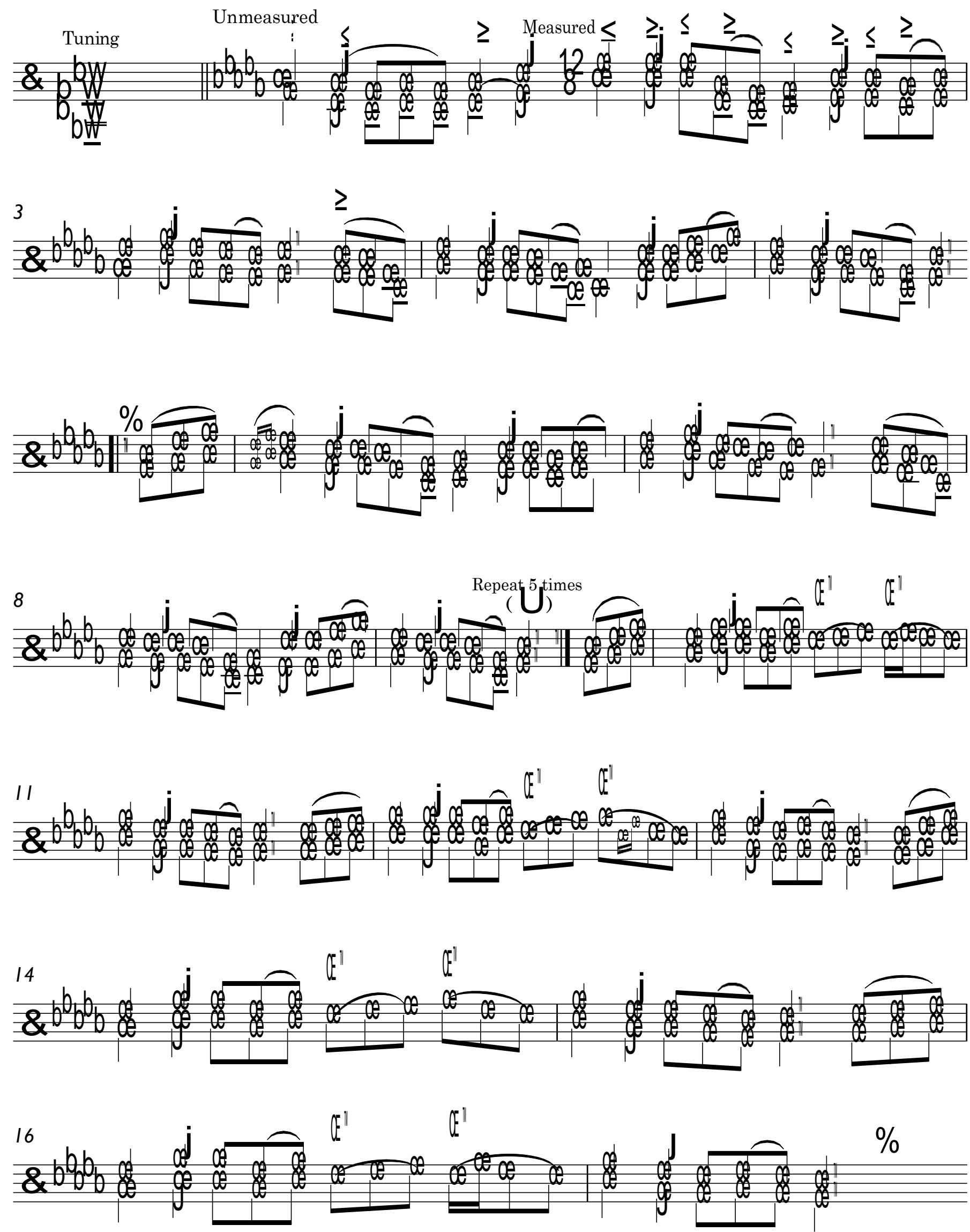


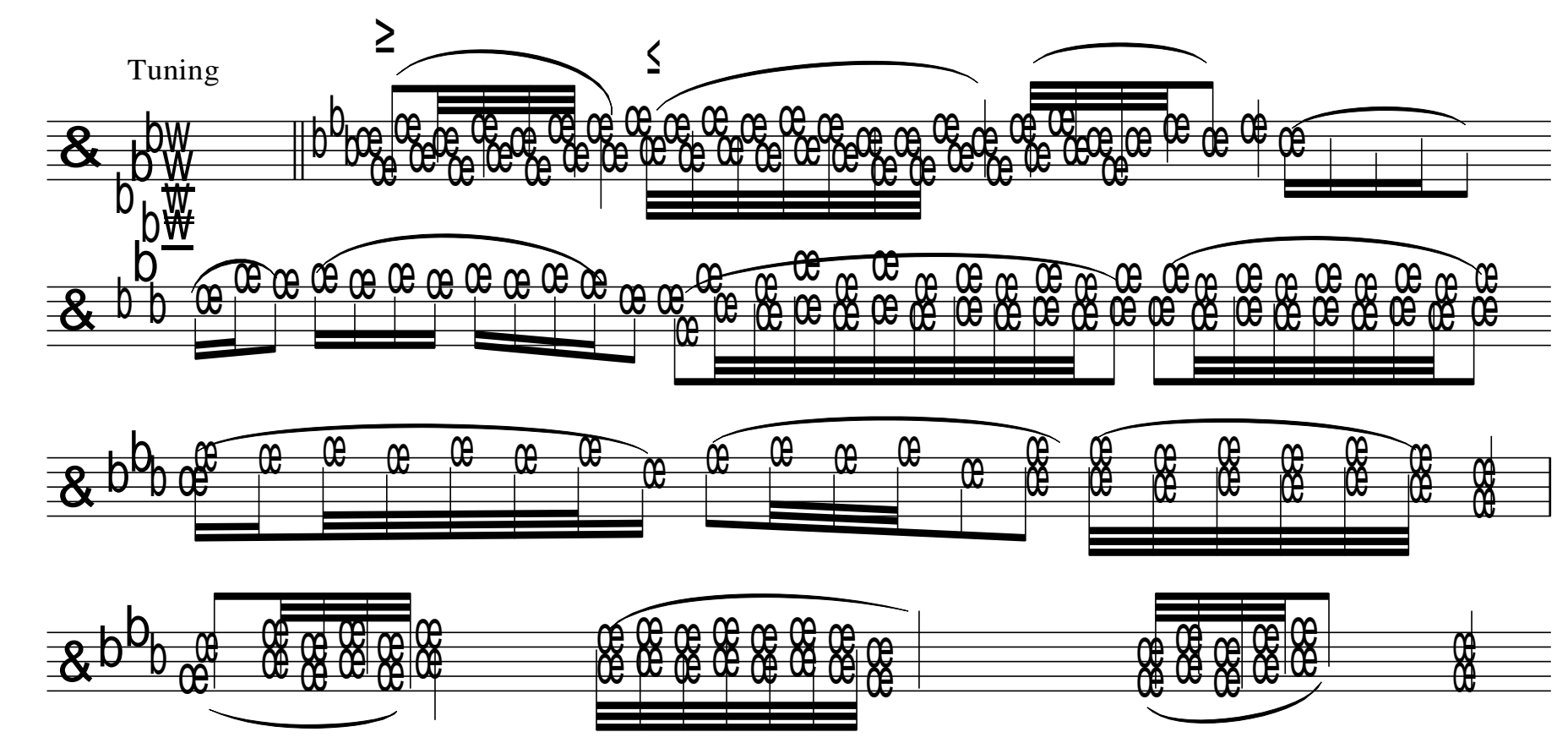

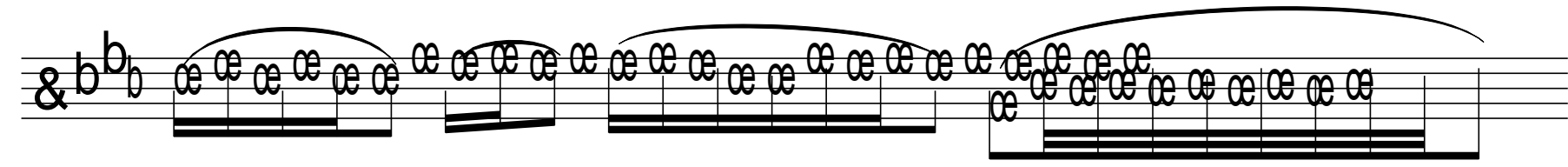

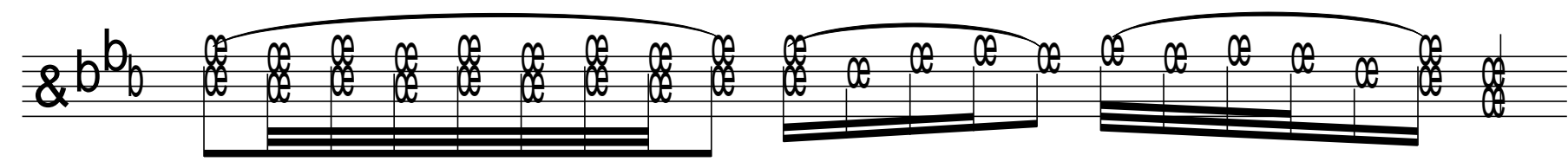

\&

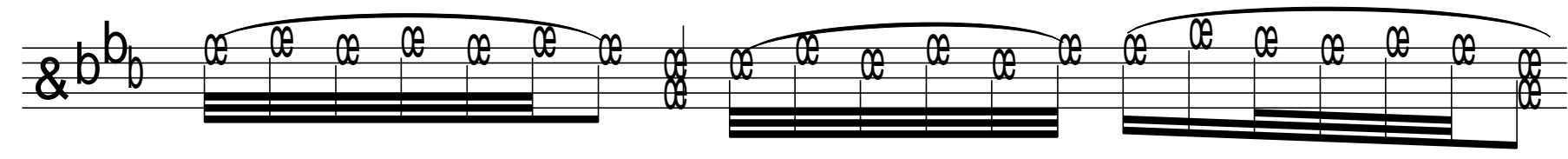

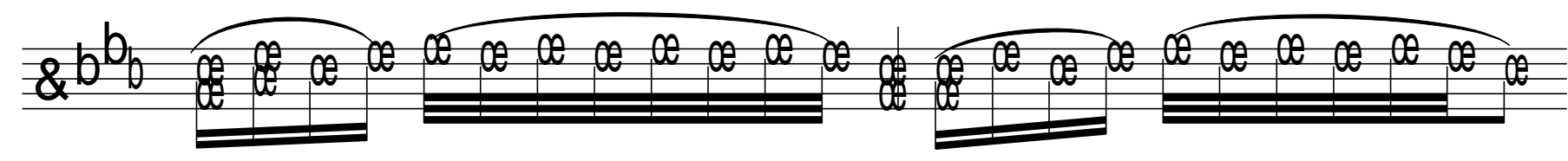

$\& b b 0$

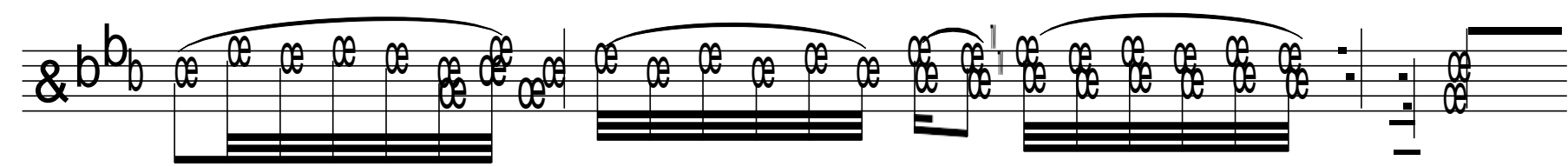




\section{University Library}

\section{- M M N E R VA A gateway to Melbourne's research publications}

Minerva Access is the Institutional Repository of The University of Melbourne

Author/s:

Irving, D

Title:

Strings across the ocean: practices, traditions, and histories of the Cocos Malay biola in the Cocos (Keeling) Islands, Indian Ocean

Date:

2020-05-07

Citation:

Irving, D. (2020). Strings across the ocean: practices, traditions, and histories of the Cocos Malay biola in the Cocos (Keeling) Islands, Indian Ocean. Ethnomusicology Forum, 28 (3), pp.283-320. https://doi.org/10.1080/17411912.2020.1754874.

Persistent Link:

http://hdl.handle.net/11343/258494 